\title{
New Cellulose based pH-Sensitive Hydrogel for Highly Efficient Dyes Removal in Water Treatment: Kinetic, Thermodynamic, Theoretical and Computational Studies
}

\section{Loubna Jabir}

Universite Mohammed Premier Oujda Faculte Pluridisciplinaire de Nador

Hayat elhammi

Universite Mohammed Premier Oujda Faculte Pluridisciplinaire de Nador

Mohammed Nor

Universite Mohammed Premier Oujda Faculte Pluridisciplinaire de Nador

Issam Jilal

Universite Mohammed Premier Oujda Faculte Pluridisciplinaire de Nador

Abderrahmane El Idrissi

Universite Mohammed Premier Oujda Faculte des Sciences

Hassan Amhamdi

Abdelmalek Essaadi University: Universite Abdelmalek Essaadi

\section{Mohamed Abou-Salama}

Universite Mohammed Premier Oujda Faculte Pluridisciplinaire de Nador

\section{Youssef El Ouardi}

Lappeenranta University of Technology: LUT University

\section{Soufian El Barkany ( $\nabla$ el_barkany@yahoo.fr)}

multidisciplinary faculty of Nador https://orcid.org/0000-0003-3756-2237

\section{Katri Laatikainen}

Lappeenranta University of Technology: LUT University

\section{Research Article}

Keywords: Carbohydrate, Cellulose adsorbent, pH-sensitive Hydrogel, Dyes Removal, Water Treatment, Isotherms, Langmuir, Molecular dynamics (MD), Simulations

Posted Date: December 23rd, 2021

DOI: https://doi.org/10.21203/rs.3.rs-1138998/v1 
License: (c) (i) This work is licensed under a Creative Commons Attribution 4.0 International License. Read Full License 
New Cellulose based pH-Sensitive Hydrogel for Highly Efficient Dyes Removal in Water Treatment: Kinetic, Thermodynamic, Theoretical and Computational Studies

Loubna Jabir*a, Hayat El-Hammi ${ }^{\text {a }}$, Nor Mohammed ${ }^{b}$, Issam Jilal ${ }^{\mathrm{a}}$, Abderrahmane El Idrissic ${ }^{\mathrm{c}}$, Hassan Amhamdi $^{\text {b }}$, Mohamed Abou-Salama ${ }^{\text {a }}$, Youssef El Ouardid,e, Soufian El Barkany*a, Katri Laatikainen ${ }^{\mathrm{e}}$

${ }^{a}$ Laboratory of Molecular Chemistry, Materials and Environment (LMCME), Department of Chemistry, Faculty Multidisciplinary Nador, Mohamed 1st University, P. B. 300, Nador 62700, Morocco.

${ }^{b}$ Applied Chemistry Unit, Sciences and Technologies Faculty, Abdelmalek Essaadi University, 32003 Al Hoceima, Morocco

${ }^{c}$ Laboratory Applied Chemistry and Environmental (LCAE-URAC18), Faculty of Sciences of Oujda, Mohamed1 stUniversity, 60000 Oujda, Morocco

${ }^{d}$ LIMOME Laboratory, Sidi Mohamed Ben Abdellah University, Faculty of Sciences Dhar El Mehraz, Dhar El Mehraz B.P. 1796 Atlas, Fes 30000, Morocco

${ }^{e}$ Lappeenranta University of Technology, Laboratory of Separation Technology, P.O. Box 20, FI- 53851 Lappeenranta, Finland.

*Corresponding authors. E-mail addresses: el.barkany011@gmail.com (Soufian El Barkany), ja.loubna@gmail.com (Loubna Jabir)

Abstract:

In this paper, a new green $\mathrm{pH}$-sensitive cellulose based hydrogel (swelling rate $~ 1005 \%$ ) was successfully elaborated. However, the new EDTA crosslinked HEC was investigated as adsorbent materiel, which it showed high removal efficiency ( 2000 mg.g $\left.{ }^{-1}\right)$ to aquatic micropollutants, especially methylene blue as cationic dyes model. The synthesis of HECEDTA at high advanced crosslinking degree (up to $92 \%$ ) that confirmed using structural analyzes (FTIR and 13C CP/MAS-NMR), was cried out using DAEDT and DMAP as acyl transfer agent, where the lamellar morphology (2D- microstructure) was highly suggested basing on the average functionality of the reaction system. The kinetic study showed that the adsorption process was better described by pseudo-second-order kinetic, where the thermodynamic parameters exhibited a negative effect of temperature indicating a physical adsorption process. In addition, the adsorption capacity was studied according to the experimental conditions ( $\mathrm{pH}$, contact time, concentration, etc.), and the Freundlich model revealed a strong correlation to the experimental results indicating an energetic heterogeneity of the surface active sites. In the other hand, molecular dynamics (MD) simulations were conducted and optimized using COMPASS II, where the results showed a good agreement with the experiment, and that basing on the intermolecular Non-covalent interaction, molecular structure and cluster configurations.

Keywords: Carbohydrate, Cellulose adsorbent, pH-sensitive Hydrogel, Dyes Removal, Water Treatment, Isotherms, Langmuir, Molecular dynamics (MD), Simulations.

\section{Introduction:}


Organic pollutants are molecules defined by their properties of toxicity and persistence in the environment as well as their bioaccumulation; they have a harmful impact on human health and the environment, and they are very difficult to purify by natural biological degradation (Pagga and Brown 1986, Pelalak, Soltani et al. 2021). Depending on their reactivity, hazardous molecules (pesticides, dyes, hydrocarbons, phenol and its derivatives, etc.) accumulate in living tissues and their concentrations increase along the trophic chain. While most dyes are not directly toxic, a significant portion of their metabolites is very harmful (Naidja 2010). Indeed, their mutagenic, teratogenic or carcinogenic effects appear after degradation of the initial molecule into oxidation by-products, e.g. carcinogenic amine for azo (Tsuda, Matsusaka et al. 2000) and leuco derivative for triphenylmethanes (Culp, Beland et al. 2002). These carcinogenic groups (in electrophilic or radical form) attack the pyrimidic bases of DNA and RNA. Therefore, they cause an alteration of the genetic code with mutation and risk of cancer. As an example, azo dyes are characterized by the presence of azo group $(-\mathrm{N}=\mathrm{N}-)$, where the breaking of the azo bonds leads to the formation of primary amines which cause methemoglobinemia that is characterized by an impediment of transport oxygen in the blood (Greene and Baughman 1996). At this stage, organic dyes that are resulted from anthropogenic activities released into the natural environment is estimated at between 15 and $20 \%$ of world production (Salah 2012). The organic dyes are among the pollutants, which pose a great risk to the environment particularly industrial effluents from textile activities, which often present a large pollutant load that is difficult to biodegrade, and which has harmful impacts on the environment and humans (Danel 1999, Rafatullah, Sulaiman et al. 2010, Gobi, Mashitah et al. 2011). However, the discoloration of textile effluents is often carried out on natural adsorbents, in particular activated carbon (Malik 2003), clay (Weng and Pan 2007) and phosphates (Barka, Qourzal et al. 2008).

Methylene blue (MB) is an intensively used cationic dye (Wilson 1907, Marr, Stewart et al. 1973, Dutta, Mukhopadhyay et al. 2001, Uddin, Islam et al. 2009, Huang, Chen et al. 2010, Rafatullah, Sulaiman et al. 2010, Sukumaran and Ramalingam 2011, Sbai, Oukili et al. 2016), derived from phenothiazine (Cenens and Schoonheydt 1988, Bolotin, Baranovsky et al. 2006), which occurs in several hydrated forms (Beer, Baumann et al. 2006, Rager, Geoffroy et al. 2012). It is commonly used as a model for an organic contaminant due to its stable molecular structure (Huang, Chen et al. 2010). During the last decades, remarkable efforts have been made to eliminate or reduce the polluting load of industrial effluents, including coagulation-fluctuation (Vandevivere, Bianchi et al. 1998, Barclay and Buckley 2000), 
precipitation (Pan, Wang et al. 2016), Reverse osmosis (Li, Lin et al. 2011), Advanced oxidation processes (POA) (Andreozzi, Caprio et al. 1999, Crini, Badot et al. 2007, Chergui 2010), Aerobic (Hitz, Huber et al. 1978, Hu 1996, Cha, Doerge et al. 2001) and anaerobic (Al-Kdasi, Idris et al. 2004) treatments. However, these methods have shown limiting drawbacks and obstacles to their application, in particular the high cost; efficiency dependence to types of dyes i.e. azo, clogging of filters, generation of highly oxidizing radical species and the formation of more toxic intermediate compounds. However, the adsorption of organic dyes on solid supports remains very limited at the surface of the adsorbent, which requires optimum morphology with a large specific surface area. On the other hand, $\mathrm{pH}-$ sensitive hydrogels allow the penetration of the contaminated solution that increase the hydrogel-pollutant contact surface, and as a non-destructive technique, a simple modification of $\mathrm{pH}$ allows the regeneration of both the organic pollutant and the hydrogel without carrying out expensive subsequent regeneration and post-treatment operations of solid waste (Mckay, Ramprasad et al. 1987).

Faced to environmental constraints that impose the friendly environmental aspect of industrial processes, several studies are directed towards the development of materials of natural origin such as chitin (Cao, Pan et al. 2018), chitosan (Melo, Paulino et al. 2018, Kellner-Rogers, Taylor et al. 2019), cellulose (Senna, Novak et al. 2013, Senna, Novack et al. 2014, Melo, Paulino et al. 2018), etc. Yet, the thermal degradation of cellulose before its melting temperature limits its treatment by thermal processes, while its insolubility in almost all usual solvents constitutes the major obstacle to chemical modifications by simple reaction routes. However, the introduction of new functionalities into the saccharide structure of cellulose requires complex, expensive and toxic solvation systems (Jilal, El-Barkany et al. 2019). In this sense, the use of cellulosic derivatives as intermediate polymers such as cellulose acetate (TABAGHT, EL IDRISSI et al. , Tenorio-Alfonso, Sánchez et al. 2019), ethyl cellulose (Ma, Gong et al. 2018), and carboxymethyl cellulose (Naderi, Lindström et al. 2015, Li, Mei et al. 2016, Hasan, Waibhaw et al. 2018, Rao, Ge et al. 2018), ... has appeared profitable for the development of new families of cellulose adsorbents. Recently, HydroxyethylCellulose (HEC) as nonionic and water-soluble cellulose derivative has received remarkable attention with excellent performance properties as a thickener (Coryell 2017, Luo, Liu et al. 2018), binder (De Guzman and Balela 2019, Hämmer, Gassmann et al. 2019, Younes, El-sharkawy et al. 2019), emulsifier (Wang, He et al. 2020, Yang, Li et al. 2020), cement set retarder (Zhi, Ma et al. 2017, Liu, Wang et al. 2019), flocculent to colloidal 
turbidity and heavy metals removal (Jilal, El Barkany et al. 2018, Chaouf, El Barkany et al. 2019, Jilal, El-Barkany et al. 2019), etc. HEC has a comparable chemical structure to that of cellulose, where the introduction of ethyl groups allows the intercalation of macromolecular chains, decreases the density of hydrogen bonds and increases reactivity via the increase in the density of primary hydroxyls. These structural properties solve the problem of solubility and therefore the feasibility of chemical modification, which has resulted in a wide variety of cellulosic materials based on HEC including heavy metal adsorbents (Choudhury, Majumdar et al. 2018, Jin, Easton et al. 2018) and dyes removal (Huang, Wu et al. 2019, Ning, Zhang et al. 2020).

In this paper, the results of structural analyzes (FTIR and 13C CP/MAS NMR) showed that the synthesis of new pH-sensitive hydrogel (HEC-EDTA) was carried out successfully, and applied with good performance as adsorbent of organic micropollutants in aquatic systems. In addition, the mean system functionality around the value $2(\approx 2 / \mathrm{AGU})$ strongly suggests a $2 \mathrm{D}$ dimensional microstructure of HEC-EDTA, and therefore, sheet morphology is expected with good penetration of pollutant-carrying liquid. The adsorption capacity was studied according to the experimental conditions ( $\mathrm{pH}$, contact time, concentration, etc.) in order to optimize the adsorption capacity. In addition, the kinetic study showed pseudo-second-order kinetics, while the thermodynamic behavior showed a negative effect of temperature indicating a physical process of adsorption, with an energetic heterogeneity of the surface active sites that are proven by a strong correlation with the Freundlich model.

To our knowledge, the material discussed in this article has never been discussed in the literature, neither in terms of synthesis and characterization nor of application as an adsorbent sensitive to $\mathrm{pH}$, hence the originality of this work. This article is part of a global energy storage study, where this material was used as precursor in the production of cathode compartments of ion batteries, which will be published soon.

\section{Materials and methods:}

\section{Materials:}

HydroxyethylCellulose (HEC, DS = 1.5) and methylene blue $(\mathrm{MB})$ were obtained from Sigma Aldrich. Ethylenediaminetetraacetic acid (EDTA), 4-dimethylaminopyridine (DMAP) and dimethylsulfoxide (DMSO) were purchased from Riedel-de Haë. The other solvents and 
chemicals are of analytical grade and were received from Sigma Aldrich where they were used without further purification.

Methods:

FTIR spectra are recorded between 400 and $4000 \mathrm{~cm}^{-1}$ on FTIR-RShimadzu type spectrometer using the pellets method, where $1 \% \mathrm{w}$ of sample was finely ground with $99 \% \mathrm{w}$ of spectroscopy grade $\mathrm{KBr}, 40$ scans were performed for each analysis at $2 \mathrm{~cm}^{-1}$ resolution. The absorbance was calculated from Uv-vis spectra performed on Uv-Shimadzu type spectrophotometer using quartz cuvettes at the wavelength of $665 \mathrm{~nm}$. UV-vis spectra were recorded in the wavelength range of 400 to $800 \mathrm{~nm}$. Elemental analyses results were achieved using Perkin Elmer Series II CHNS/O Model 2400 analyzer. ${ }^{13} \mathrm{C}$ NMR spectra acquired with Cross-Polarization Magic Angle Spinning (solid-state CP/MAS 13C NMR) spectrum was recorded on a Bruker DRX-400 spectrometer with a frequency of $100 \mathrm{MHz}$, and 1800 scans were recorded with the $90^{\circ}$ pulse time of $4.85 \mu$ s at room temperature. The acquisition time and the delay time were $0.032 \mathrm{~s}$ and $2 \mathrm{~s}$, respectively. The surface charge of materiel was evaluated using the zeta potential $(\zeta)$ against $\mathrm{pH}(2-11)$ in Milli-Q water at $0.1 \%$, and the results were recorded at $25 \pm 0.1{ }^{\circ} \mathrm{C}$ using Zetasizer Nano ZS (Malvern Instruments).

\section{Preparation of HEC-EDTA:}

$3 \mathrm{~g}(13.16 \mathrm{mmol} / \mathrm{AGU})$ of HEC in 40ml of DMSO were slowly added by an addition funnel to $5 \mathrm{~g}(19.51 \mathrm{mmol})$ of EDTAD (prepared according to the method described by Capretta et al.(Capretta, Maharajh et al. 1995, Júnior, Gurgel et al. 2009, Senna, Novack et al. 2014) and $0.5 \mathrm{~g}$ (4 mmol) of DMAP as catalyst (acyl transfer reagent) dissolved in $15 \mathrm{ml}$ of DMSO, and the reaction mixture was stirred for $4 \mathrm{~h}$ at $60^{\circ} \mathrm{C}$. At the end of the reaction, HEC-EDTA was precipitated in acetone, filtered under vacuum, washed with acetone, thus a white powder was obtained which became gelatinous after washing with a saturated sodium bicarbonate solution of $\mathrm{NaHCO}_{3}$.

Measurement of swelling degree:

The swelling degree (S \%) was determined according to ASTM, 1979 and ASTM123955. In short, the gels $(0.1 \mathrm{~g})$ were immersed in deionized water and taken out at different consecutive time intervals. After equilibrium, the swollen samples were separated using a 100-mesh filter-bag and dried to drain the excess water. Then, the swollen samples were 
weighed and the swelling degree (S \%) of the hydrogel was calculated from the following equation (eq. 1) :

$$
S(\%)=\left(W_{e}-W_{i}\right) / W_{i}
$$

$W i$ and We are the initial weight of the dried hydrogel $(\mathrm{g})$ and the weight of gel at equilibrium $(\mathrm{g})$.

\section{Adsorption experiment:}

MB adsorption experiments on HEC-EDTA were performed in the range of initial concentrations of 10 to $600 \mathrm{mg} .1-1$ of aqueous BM solutions. The kinetic study was performed by varying the contact time from 0 to $40 \mathrm{~min}$. The batches were carried out by stirring a quantity of $30 \mathrm{mg}$ of HEC-EDTA gel in $10 \mathrm{ml}$ of BM solution, and the $\mathrm{pH}$ was set at a value of 8 for $30 \mathrm{~min}$ as a contact time. The effect of $\mathrm{pH}(2-11)$ and gel dose $\left(0.15-0.6\right.$ g.L $\left.\mathrm{L}^{-1}\right)$ on adsorption capacity were investigated. However, the thermodynamic study was carried out in a temperature range of 20 to $60^{\circ} \mathrm{C}$. The concentration of $\mathrm{BM}$ before and after adsorption was determined by measuring the absorbance of the solution at $\lambda_{\max }=662 \mathrm{~nm}$, while the adsorption capacity per unit mass of HEC-EDTA and the removal rate (R \%) were calculated from the equation 2 and 3 , respectively.

$$
\begin{aligned}
& q=\left(C_{0}-C_{e}\right) \cdot V / M \\
& R(\%)=1-C_{e} / C_{0}
\end{aligned}
$$

Where, $\mathrm{q}\left(\mathrm{mg} \cdot \mathrm{g}^{-1}\right)$ is the equilibrium adsorption capacity at thermodynamic equilibrium, $\mathrm{C}_{0}$ (mg. $\mathrm{L}^{-1}$ ) and $\mathrm{C}_{\mathrm{e}}\left(\mathrm{mg} . \mathrm{L}^{-1}\right.$ ) are the initial and the equilibrium concentration of the BM solution, respectively. V (L) is the volume of the BM solution and $\mathrm{M}(\mathrm{g})$ is the weight of the HECEDTA adsorbent.

\section{Results and discussions:}

\section{Synthesis and characterization of HEC-EDTA:}

The crosslinking of HEC by EDTA was carried out to modify its hydrophilic character and to prevent its solubility in water, where this modification allows HEC-EDTA to be used as an adsorbent for the present micropollutants in aquatic environments (liquid-solid extraction). In this study, the crosslinking was carried out by the creation of ester bridges between the 
191 primary hydroxyl groups of HEC and EDTA. However, to increase the reactivity of the carboxylic functions of EDTA, a trans-anhydridation reaction between EDTA and acetic anhydride was carried out. The functionalization of HEC was carried out in DMSO as homogeneous medium in the presence of DMAP as esterification agent, where a notable increase in the viscosity of the reaction medium was noted during the reaction, which indicates the supramolecular crosslinking of the cellulosic chains (Fig. 1a). EDTA crosslinked HEC hydrogel was recovered in its acidic form by precipitation in acetone and frequent washing with the same solvent and deionized water. In addition, to release the carboxylate functions, the treatments of HEC-EDTA powder with a saturated sodium bicarbonate solution (and then by deionized water until the filtrate neutralization) have caused a radical change in the appearance of the product that became, more and more, gelatinous.

Fig. lb shows the kinetic study of swelling of the HEC-EDTA hydrogel at $25{ }^{\circ} \mathrm{C}$. The significant swelling rate observed from the first contact with the solvent $\left(\mathrm{H}_{2} \mathrm{O}\right)$ at 40 min can be attributed to the highly hygroscopic character of the sodium EDTA and its instability when exposed to moisture (Gbadamosi, Famuwagun et al. 2018). In addition, the hydrophilic behavior of HEC and its good solubility in the aquatic environment significantly improved the water absorption of the hydrogel, as well as the crosslinking by EDTA prevented the water solubility of HEC which could improve the steric stability to retain more water in the network (Calcagnile, Sibillano et al. 2019), and consequently, the rate of swelling increased gradually with the time of immersion to reach a maximum value of 950 to $1005 \%$ after $35 \mathrm{~min}$. In the case of functional hydrogels, intended for ecological applications including processes for removing the pollutant load from industrial effluents, the high swelling and the hygroscopic nature rate increases the internal surface area for the better penetration, which allows more adsorption sites to be fully exposed to pollutant (Elbedwehy and Atta 2020). 

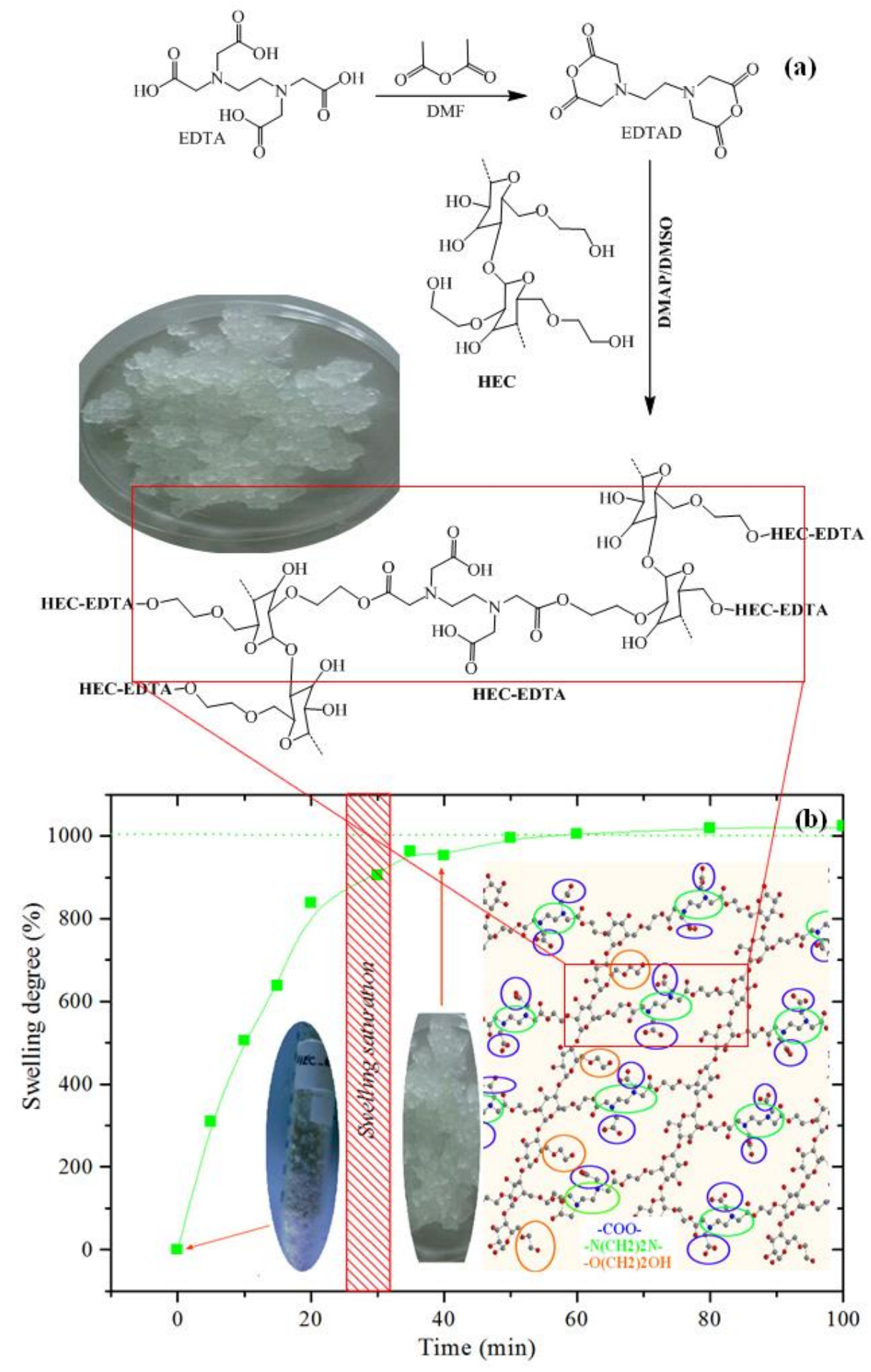

216 Fig. 1: a) HEC-EDTA synthesis reaction scheme and b) Degree of swelling against emersion time of EDTA crosslinked HEC hydrogel

218 Fig. 2a represents the FTIR spectra of untreated (EDTA) and treated EDTA (EDTAD). 219 However, the treatment of EDTA with acetic anhydride showed a remarkable changes in the 220 general vibrational aspect of EDTA, where the appearance, on the EDTAD spectrum, of new 
221 absorption bands between $1761 \mathrm{~cm}^{-1}$ and $1809 \mathrm{~cm}^{-1}$ assigned to the anhydride carbonyl (CO)

222 vibrations (symmetric and antisymmetric), indicating that the trans-anhydridation reaction 223 between EDTA and acetic anhydride was carried out successively. Fig. $2 b$ shows the 224 vibrational spectra (FTIR) of unmodified HEC and HEC-EDTA before and after 225 saponification using a saturated sodium bicarbonate solution.
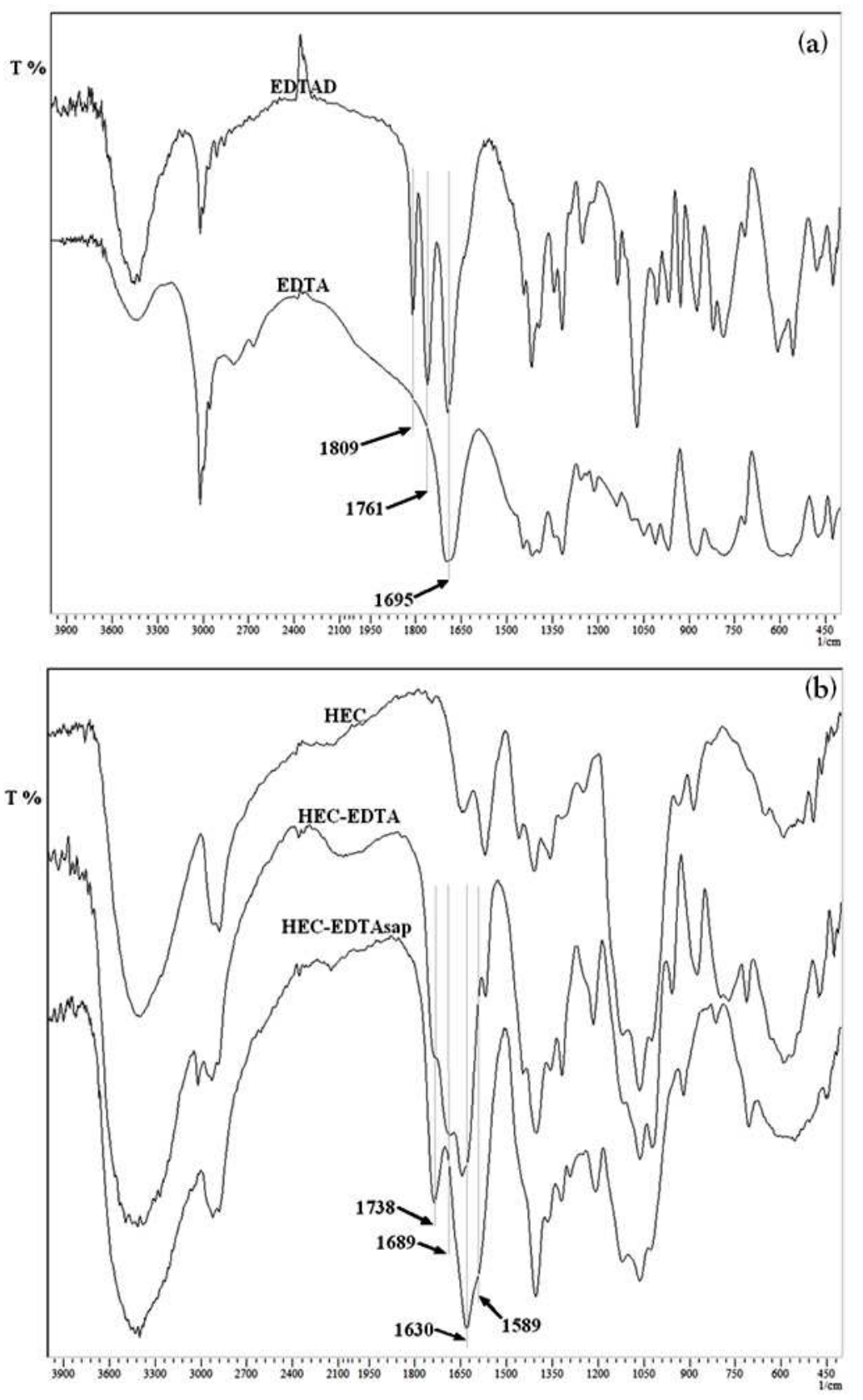

Fig. 2. FTIR spectra of (a) acid and anhydride forms of EDTA and (b) HEC-EDTA and saponified HEC-EDTA 
The spectrum of HEC indicates a strong adsorption band intensity at $3412 \mathrm{~cm}^{-1}$ characteristic of the $\mathrm{OH}$ hydroxide group of polysaccharides structures (Pradeep 2009), while a distinguished band around $1355 \mathrm{~cm}^{-1}$ was attributed to the deformation vibrations in the plane of the $\mathrm{OH}$ function of the alcohol group (Zafar, Aqil et al. 2007). The absorption band located at $1060 \mathrm{~cm}^{-1}$ corresponds to COC stretching vibration in glucopyranose (Silverstein, Bassler et al. 1991), where that around $1120 \mathrm{~cm}^{-1}$ has been attributed to the asymmetric $\mathrm{CO}$ vibration (Zare, Motahari et al. 2018).

The spectrum corresponds to HEC-EDTA highlights the esterification reaction via the appearance of new absorption bands characteristic of grafted entities (EDTA). However, the band observed at $1689 \mathrm{~cm}^{-1}$ is attributed to the acid carboxylic carbonyl groups (CO), while the band located at $1630 \mathrm{~cm}^{-1}$ corresponds to the deformation of naturally absorbed water. The appearance of a new absorption band located at $1738 \mathrm{~cm}^{-1}$ corresponds to the carbonyl ester group reveals the successful grafting of EDTA on HEC. After saponification, the shift of the band attributed to the acid carbonyl from $1689 \mathrm{~cm}^{-1}$ to $1589 \mathrm{~cm}^{-1}$, indicating the transformation to the carboxylate form $\left(\mathrm{COO}^{-}, \mathrm{Na}^{+}\right)$under the action of $\mathrm{NaHCO}_{3}$, is another strong indication of the incorporation of the carboxylic functions on the surface of the cellulosic material (HEC). The creation of the negatively charged character (carboxylate) is an encouragement to consider HEC-EDTA as a candidate to be effective adsorbent for the removal of cationic dyes like BM.

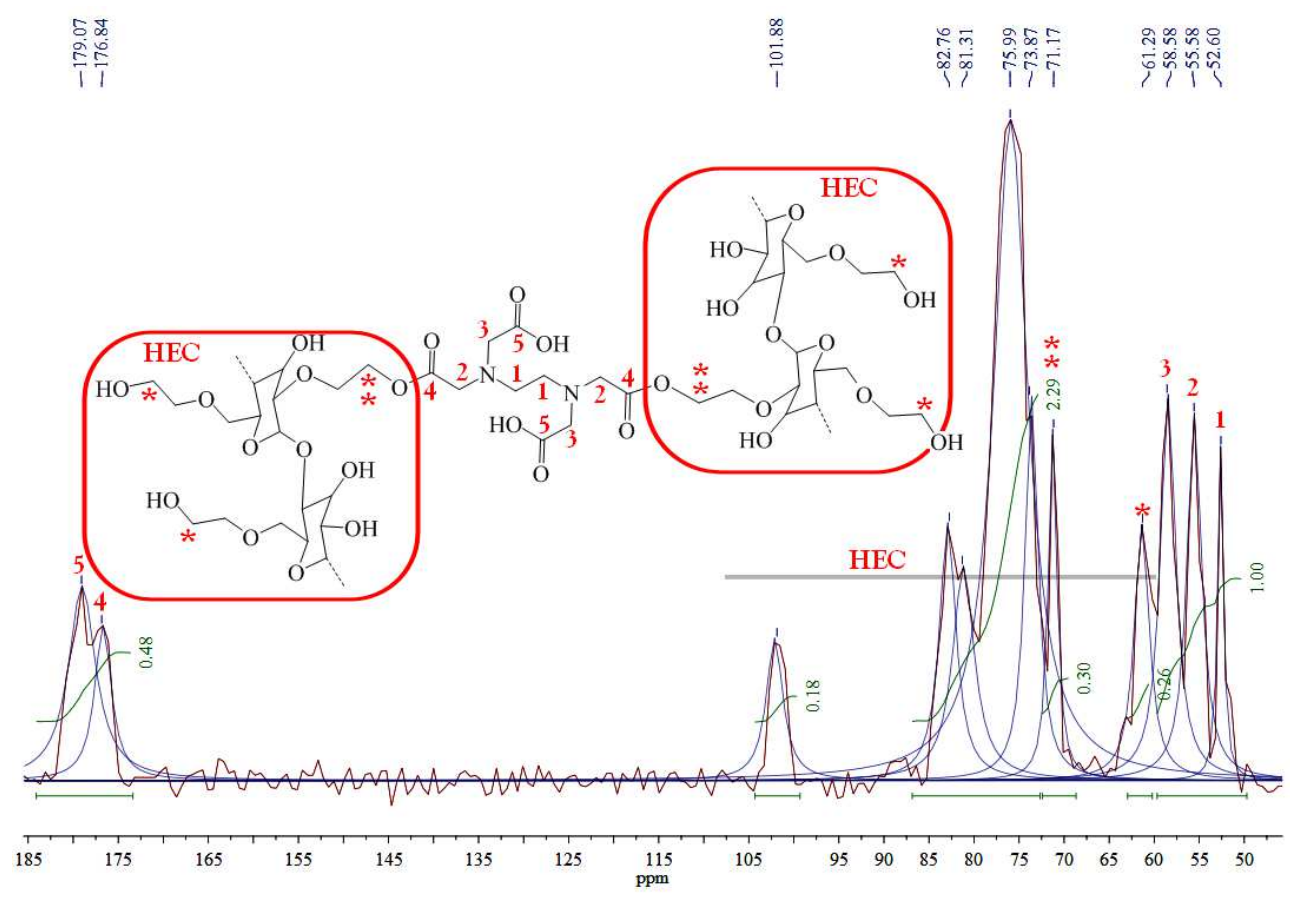

Fig. 3. Solid-state CP/MAS ${ }^{13} \mathrm{C}-\mathrm{NMR}$ spectrum of HEC-EDTA 
The solid-state CP/MAS ${ }^{13}$ CNMR spectrum of HEC-EDTA (Fig. 3) reflects the various structural modifications of HEC resulting from EDTA crosslinking reaction. The number of Hydroxyethyl groups (DS) in the starting material (HEC) is estimated in our previous papers around $\mathrm{DS}_{\mathrm{HEC}} \simeq 1.5$, based on the integrations of proton signals, on the ${ }^{1} \mathrm{H}$ NMR spectra, of C6-methylene cellulose and grafted methylene Hydroxyethyl (Jilal, El Barkany et al. 2018, Chaouf, El Barkany et al. 2019), and this result is exploited in the following steps to calculate the degree of substitution of EDTA in this work $\left(\mathrm{DS}_{\mathrm{EDTA}}\right)$. Signals of broad-ringed cellulose skeletal carbon (HEC) are recorded between 60 and 105 ppm (Jilal, El Barkany et al. 2018). However, the appearance of a new methylene carbon signal at $71.2 \mathrm{ppm}(* *)$ is attributed to the chemical shift of typical methylene carbon signals of HEC detected at $61.3 \mathrm{ppm}(*)$, that is a strong signal of the change in the $(*)$ carbon chemical environment, caused by EDTA chemical modification of HEC, where also a positive result of successful grafting reaction is shown. Furthermore, the value of $\operatorname{DS}_{\mathrm{EDTA}}(\simeq 0.8)$ was calculated from ${ }^{13} \mathrm{C}$ NMR spectrum of HEC-EDTA sample shown on Fig. 3, and based on the integrations of the carbonic signals I* $(\simeq 0.26)$ and $\mathrm{I} * *(\simeq 0.30)$, using the following equation $(E q .4)$ :

$$
D S_{E D T A}=1.5 \frac{I^{* *}}{I^{* *}+I^{*}}
$$

The ${ }^{13} \mathrm{C}$ solid NMR spectrum (Fig. 3) reveals evidence of grafting and crosslinking reaction by examining the ratio of signal integrations of carbonyl esters binding EDTA entities grafted to HEC chains, which are located at $176.8 \mathrm{ppm}$ (4), and those of free carbonyl acids detected at $179.1 \mathrm{ppm}$ (5). Values close to $\mathrm{I}_{4}(0.23)$ and $\mathrm{I}_{5}(0.25)$ indicate a high crosslinking density. Besides, the degree of crosslinking $(D c \%)$ is estimated to be around 92 $\%$ using the equation 5 (eq. 5 ) :

$$
D_{C}(\%)=\left(3-4 \frac{I_{5}}{I_{5}+I_{4}}\right) \times 100
$$

This trend, corresponding to the high level of crosslinking, is confirmed by the closest values of the integrations of the signals attributed to the methylene carbons of the grafted EDTA at 52.6, 55.6 and 58.6 ppm (Fig. 3) assigned to the EDTA carbons (1), (2) and (3), respectively. Furthermore, the integration ratio close to the value of 1 between the two typical peaks (2) in $\alpha$-ester and (3) in $\alpha$-acid is a strong indication of the predominance of the crosslinked form of the hydrogel. 
Besides the NMR, spectral results of HEC-EDTA reported in Fig. 3 confirm those obtained by FTIR vibrational spectroscopy (Fig.2a). In addition, the proposed structure of the new hydrogel developed in this paper is confirmed and completed by the study of the elemental profile for a $\mathrm{DS}_{\mathrm{EDTA}}$ of 0.8 , and the results are reported in Table 1 . Before getting into the study of the elemental profile, there is a need to note that the elemental composition is very sensitive toward the structure and bonding variability of hydrogel network. However, experimental data from the elemental analysis of hydrogel (HEC-EDTA ${ }^{\exp }$ ) showed that the EDTA crosslinking reaction of HEC, under homogeneous conditions, slightly decreased the proportion of carbon (from 47.37 to $47.23 \%$ ) and hydrogen (from 7.02 to $6.36 \%$ ), where the appearance of higher nitrogen content (3.05\%), compared to the HEC starting material (0.00 $\%$ ), could prove the introduction of EDTA as a crosslinking agent.

\begin{tabular}{|c|c|c|c|c|c|}
\hline & \multicolumn{3}{|c|}{ Atomic wt. \% } & \multirow{2}{*}{$\mathrm{DS}_{\mathrm{EDTA}}$} & \multirow{2}{*}{$\mathrm{D}_{\mathrm{C}} \%$} \\
\hline & C & $\mathrm{N}$ & $\mathrm{H}$ & & \\
\hline HEC & 47.37 & 0.00 & 7.02 & 0.00 & 0.00 \\
\hline HEC-EDTA $^{\exp }$ & 47.23 & 3.05 & 6.36 & 0.80 & 92.0 \\
\hline HEC-EDTA $^{\text {th } *}$ & 47.22 & 3.39 & 6.30 & 0.80 & 100 \\
\hline HEC-EDTA $^{\text {th0 }}$ & 45.60 & 5.01 & 6.08 & 0.80 & 0.00 \\
\hline
\end{tabular}

exp: Synthesized in this work, th* : Completely crosslinking and $t h^{0}:$ Without crosslinking

Table 1. Elemental analysis of HEC (DS0) and EDTA-HEC (DS0.8)

On the other hand, the theoretical elemental compositions (HCN) of the hydrogel (HECEDTA $^{\text {th }}$ ) of the extreme values at the level of degree of crosslinking (HEC-EDTA ${ }^{\text {th* }}$ for Dc $=$ $100 \%$ and HEC-EDTA ${ }^{\text {th0 }}$ for Dc $=0 \%$ ) have been calculated. Thus, it was noted that the elemental analysis profile for the same degree of substitution $\left(\mathrm{DS}_{\mathrm{EDTA}}=0.80\right)$, and for a crosslinked polyfunctional samples (as in the case of polysaccharides), is strongly affected by the degree of crosslinking (Dc \%). This result can be explained considering the superficial and the core network EDTA distribution in hydrogel materials. Since, in highest degree of crosslinking, the sharing of each EDTA unit between two AGUs is more considered, while in the materials with lower Dc\%, each AGU keeps its EDTA unit. In the case of HEC-EDTA, it is acceptable to have a greater values of Nitrogen content $(5.01 \%)$ for a free system (without crosslinking) and around half (3.39\%) in the case of a fully crosslinked system, indicating that the EDTA moiety is inversely proportional to the degree of crosslinking. In fact, the elemental analysis experimental data were very close to those theoretical characterizing a fully crosslinked system at a $\mathrm{DS}_{\mathrm{EDTA}}$ value equal to 0.80 . This also confirms the high Dc $\%$ value of $92 \%$ characteristic of the gelatinous system in this work. In comparison with the 
results that are published recently (Zannagui, Amhamdi et al. 2020), drastic differences can be caused, by the variation of the values of DS and Dc \%, in terms of physicochemical properties particularly the powder-gel aspect, water solubility, swelling, accessibility, etc.

\section{Application of HEC-EDTA to dyes removal in Water Treatment}

\section{Effect of contact time and kinetic study}

The adsorption kinetic describes the variation of the concentration of adsorbate in the solution as a function of contact time. In order to determine the mechanism limiting the kinetics of the adsorption process, three models were applied during this study, the pseudofirst order, the pseudo-second order and the interparticle diffusion models. Fig. 4a shows the contact time effect on the evolution of MB adsorption capacity of HEC-EDTA, where the initial concentration of cationic dye $\left(\mathrm{C}_{0}\right)$ was set at $300 \mathrm{mg}$. $\mathrm{L}^{-1}$, pH8 and $30 \mathrm{mg}$ of geladsorbent. The adsorption kinetic behavior of MB on HEC-EDTA is characterized by a high rate in the initial stage (first $10 \mathrm{~min}$ ) indicating a high accessibility to the adsorption sites, and then adsorption process progressed with low increasing of the adsorption capacity to reach the equilibrium. The time to equilibrium was $30 \mathrm{~min}$ as the optimal contact time, and the maximum adsorption capacity was around $953 \mathrm{mg} \cdot \mathrm{g}^{-1}$.

At the kinetic level, in the pseudo first order model, the adsorption rate is proportional to the variation of the adsorption capacity between the equilibrium and at the time (Eq. 6$), \mathrm{k}_{1}$ is the rate constant $\left(\mathrm{min}^{-1}\right)$. By integrating and applying the initial conditions $\left(\mathrm{t}_{0}=0 \rightarrow \mathrm{q}_{\mathrm{t}}=\mathrm{q}_{0}=0\right.$ and $\mathrm{t}=\mathrm{t}_{\mathrm{e}} \rightarrow \mathrm{q}_{\mathrm{t}}=\mathrm{q}_{\mathrm{e}}$ ) the previous equation takes the linear following form (Eq. 7), $\mathrm{k}_{1}$ and $\mathrm{q}_{\mathrm{e}}$ are obtained by plotting $\ln \left(\mathrm{q}_{\mathrm{e}}-\mathrm{q}_{\mathrm{t}}\right)$ against time. On the other hand, the pseudo second order model gives the adsorption rate proportionally to the square variation of the adsorption capacity between the equilibrium and at the $\mathrm{t}$ time $(E q .8), \mathrm{k}_{2}$ is the rate constant $\left(\mathrm{g}^{\mathrm{m}} \mathrm{mg}^{-1} \cdot \mathrm{min}^{-}\right.$ $\left.{ }^{1}\right)$. However, the linear form (Eq. 9) of the previous equation (eq. 8) was obtained by integrating and applying the initial conditions $\left(\mathrm{t}_{0}=0 \rightarrow \mathrm{q}_{\mathrm{t}}=\mathrm{q}_{0}=0\right.$ and $\left.\mathrm{t}=\mathrm{t}_{\mathrm{e}} \rightarrow \mathrm{q}_{\mathrm{t}}=\mathrm{q}_{\mathrm{e}}\right), \mathrm{q}_{\mathrm{e}}$ and $\mathrm{k}_{2}$ are obtained by plotting $t / q_{t}=f(t)$.

$$
\begin{aligned}
& \frac{d q_{t}}{d t}=k_{1}\left(q_{e-} q_{t)}\right. \\
& \left.\ln \left(q_{e-} q_{t}\right)=l n q_{e}-k_{1} t \quad \text { (eq. } \text { eq }\right) \\
& \frac{d q_{t}}{d t}=k_{2}\left(q_{e}-q_{t}\right)^{2}
\end{aligned}
$$




$$
\frac{t}{q t}=\frac{1}{k_{2} q_{e}^{2}}+\frac{1}{q_{e}} \cdot t
$$

$$
q_{t}=k_{\text {int }} \cdot t^{1 / 2}+C
$$

To investigate the kinetic profile of MB adsorption onto HEC-EDTA gel, the kinetic data were fitted according to the linear form of pseudo-first-order and pseudo-second-order kinetic models, hence the conventional linear regression of the kinetic results for the two kinetic models are shown in Figure 4a. The comparison of the coefficient correlation $(\mathrm{R})$ of the linear regression was carried out to confirm the validity of the kinetic models and to examine absorption kinetic process. Thus, kinetic parameters results of the two models, summarized in table 2, show that the pseudo-second-order kinetic model provided better correlation, with high coefficient of determination value $\left(\mathrm{R}^{2} \sim 0.9998\right)$, than that of pseudo-first-order kinetic model $\left(\mathrm{R}^{2} \sim 0.9870\right)$. Moreover, the calculated qe value derived from pseudo-second-order (table 2) is consistent well with the experimental value, which indicates that the MB adsorption process kinetic on EDTA crosslinked HEC gel was better described by pseudosecond-order kinetic model.

\begin{tabular}{lccc}
\hline & $\mathrm{k}$ & $\mathrm{qe}\left(\mathrm{mg} \cdot \mathrm{g}^{-1}\right)$ & $\mathrm{R}^{2}$ \\
\hline pseudo- first order & 0.132 & 49.15 & 0.9870 \\
pseudo-second order & $6.810^{-3}$ & 957.9 & 0.9998 \\
\hline
\end{tabular}

Table 2. Kinetic parameters of pseudo-first-order and pseudo-second-order kinetic models for MB adsorption onto HEC-EDTA gel

Meanwhile, the study of intraparticle scattering was performed basing on Weber-Morries intra-particle diffusion model (Mabel, Sundararaman et al. 2019) described by eq. 10, where $\mathrm{k}_{\text {int }}$ is the rate constant of intraparticle diffusion model $\left(\mathrm{mg} \cdot \mathrm{g}^{-1} \cdot \mathrm{min}^{-1 / 2}\right)$, and $\mathrm{C}$ is a constant involved in the thickness of the boundary layer of the intraparticle diffusion model (mg. $\left.\mathrm{g}^{-1}\right)$. Figure $4 \mathrm{~b}$ shows linear fitted data of intraparticle diffusion kinetic model, where the kinetic parameters $\left(\mathrm{k}_{\mathrm{int}}\right.$ and $\mathrm{C}$ ) were derived from the slope of the linear part of the intraparticle model plots and intersection point at the origin, respectively.

According to Weber-Morris intraparticle kinetic model, the adsorption process is strictly controlled by intraparticle diffusion if $\mathrm{q}_{\mathrm{t}}$ variation against $\mathrm{t}^{1 / 2}$ is straight line. So, the apparition of three regions of linearity, shown on Fig. 4b, is a strong indication of that the intraparticle diffusion is not the only rate limiting step in the adsorption process. Whereas, the 
363 first step $\left(t^{1 / 2}\right.$ between 0 and $\left.1 \mathrm{~min}^{1 / 2}\right)$ showed an interparticle diffusion behavior, 364 characterized by a steep slope $\left(k_{\operatorname{int}(1)}=832 \mathrm{mg} \cdot \mathrm{g}^{-1} \cdot \mathrm{min}^{-1 / 2}\right)$, and correlated to the diffusion of 365 MB from the bulk solution to the boundary layer surrounding on the external adsorption surface of the adsorbent. During first contact, the low recovery rate and the high density of active accessible sites, on the external surface of HEC-EDTA (that can be occupied by adsorbate), makes this step the fastest process (Han, Wang et al. 2011), and therefore a rate controlling step.
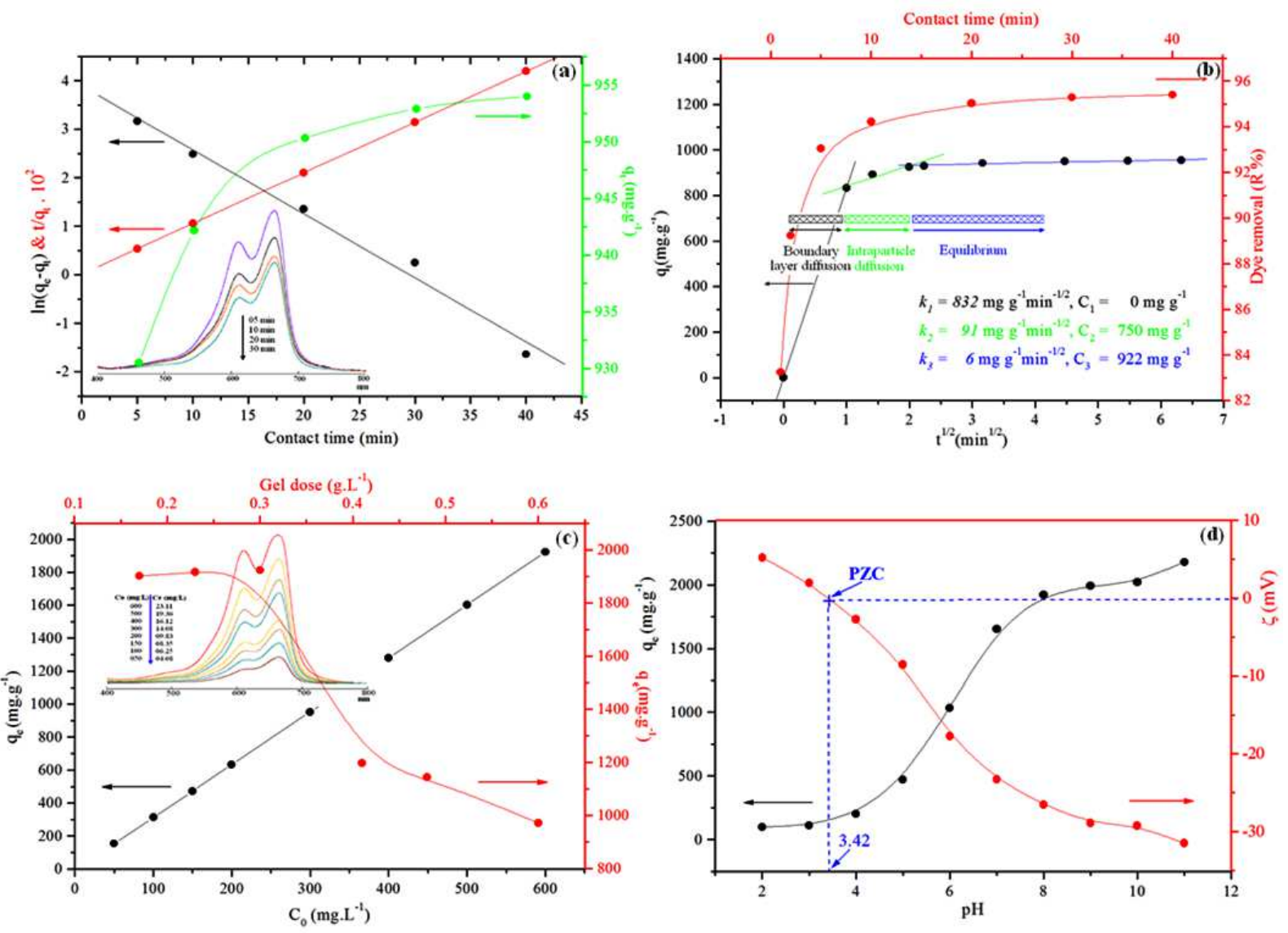

371 Fig. 4: (a) Contact time effect and kinetic models, (b) intraparticle diffusion model and dye 37pemoval, (c) gel dose and $\mathrm{C}_{0}$ effects and (d) $\mathrm{pH}$ effect on zeta potential of the gel-adsorbent and on adsorption capacity

Whereas, the second linear part $\left(t^{1 / 2}\right.$ between 1 and $\left.2.5 \mathrm{~min}^{1 / 2}\right)$ indicated by a slight slope $375\left(k_{\text {int }(2)}=91 \mathrm{mg} \cdot \mathrm{g}^{-1} \cdot \mathrm{min}^{-1 / 2}\right)$ compared to the previous step, indicates the gradual decrease in the 376 adsorption rate, where the change in adsorption process turns from interparticle diffusion to 377 intraparticle one. Indeed, when the gel external surface adsorption sites (HEC-EDTA) are consumed, the adsorbate molecules (MB) penetrate and anchor into the pore sites via an 
intraparticle diffusion, and this under the osmotic pressure generated by the different concentration gradients of dye molecules in the solution, which drove the filling and diffusion through additional internal surfaces (Liu, Tian et al. 2019). Although, the last linear part showed a very low slope $\left(k_{\text {int }(2)}=6 \mathrm{mg} \cdot \mathrm{g}^{-1} \cdot \mathrm{min}^{-1 / 2}\right)$ indicating the stability of the capacity adsorption, and that the adsorption system has reached equilibrium.

\section{Gel dose, initial concentration and $\mathrm{pH}$ effects}

The adsorbent dose effect is an important parameter to enhance the absorption capacity for dye removal, and to understand the mechanism profile of adsorption process. However, the variation of the adsorption capacity (qe) against gel dose $\left(0.1-0.6\right.$ g. $\mathrm{L}^{-1}, C_{0}=600 \mathrm{mg} . \mathrm{L}^{-1}$ and $p H=8.0$ ) was illustrated on Figure 4c. However, it can be seen that the adsorption capacity slightly increased with increasing of gel dose from 0.1 to 0.3 g.L.- ${ }^{-1}$, where the adsorption capacity moved from 1902 to $1923 \mathrm{mg} \cdot \mathrm{g}^{-1}$, while the MB removal ratio (R\%) increased from $53.88 \%$ to $73.44 \%$ and to $96.15 \%$ for $0.17,0.23$ and 0.3 g.L.-1 gel doses, respectively. Then, beyond 0.3 g. $\mathrm{L}^{-1}$, the change in the adsorption capacity of MB was inversely proportional to the gel dose, where the ability to eliminate MB decreased from 1923, 1196 and $1142 \mathrm{mg} \cdot \mathrm{g}^{-1}$ to $971 \mathrm{mg} \cdot \mathrm{g}^{-1}$ with increasing gelatinous load from $0.3,0.41$, 0.48 to $0.6 \mathrm{~g} . \mathrm{L}^{-1}$. In addition, the calculated values of the removal rate $(\mathrm{R} \%)$, in the adsorbent dose range higher than $0.3 \mathrm{~g}$. $\mathrm{L}^{-1}$, were optimal and greater than $90 \%$.

This behavior can be explained by adsorption resistance, which results from resistance to mass transfer between external and internal surface under osmotic pressure, which affecting the value of driving forces. Hence, faced with the high availability of vacant sites, adsorption would easily reach equilibrium, while other more active sites will not be available and this because of their aggregation and the lengthening of the diffusion path, and consequently, the decrease in the total available surface and the reduction in the adsorption capacity of the material. In addition, it is evident that the low rate of recovery of the active sites causes a low adsorption capacity. At light of this phenomenon, figure $4 \mathrm{c}$ shows an overview of the influence of gel dose on the elimination capacity of $\mathrm{MB}$, so the dose $0.3 \mathrm{~g} . \mathrm{L}^{-1}$ was selected as an optimal value, indicating that the active sites can be used efficiently, leading to a higher adsorption capacity.

The initial dye concentration is another significant factor that determines the effectiveness of the adsorption process. However, the effect of the initial concentration of the MB solution 
on the adsorption ability of HEC-EDTA is shown in Fig. 4c, where the experiments were carried out within the initial concentration range of $50-600 \mathrm{mg} \mathrm{L}^{-1}\left(25^{\circ} \mathrm{C}, \mathrm{pH}\right.$, gel dose : 0.3 $\mathrm{g} \mathrm{L}^{-1}$ ). Keeping all the other parameters constant, the results indicate that the adsorption capacity increased linearly over the initial concentration range of $50-600 \mathrm{mg} \mathrm{L}^{-1}$, suggesting that the qe values greatly depended on the initial concentration of MB solution. Indeed, increasing the dye initial concentration induce concentration gradient, that generates motrice forces pushing MB towards the adsorbent internal area. On the other hand, more than the difference is large in MB concentration between the solution bulk and the adsorbent area, the migration rate is greater, where increasing the concentration gradient promotes a high probability of collision between MB molecules and active sites on the adsorbent surface. Furthermore, in front of the continuous increase of the adsorption capacity against initial concentration of the organic dye, the formation of the multilayers is strongly suggested. This suggestion can be confirmed by the irrationality of models describing the single-layer adsorption, in particular the Langmuir model (Fig. 5a).

The $\mathrm{pH}$ of dye solution is an extensive factor that affecting the efficiency of absorption process, where drastically affect both the electrical behavior and the charge density of the adsorbent and the adsorbate, thus governing the adsorbent-adsorbate interaction mechanism. To investigate the $\mathrm{pH}$ solution effect on the adsorption efficiency, $0.3 \mathrm{~g} \mathrm{~L}^{-1}$ gel dose was used to $600 \mathrm{mg}$. $\mathrm{L}^{-1} \mathrm{MB}$ initial concentration solution at room temperature $\left(25^{\circ} \mathrm{C}\right)$, where the $\mathrm{pH}$ solution $(2-11)$ was adjusted using $\mathrm{HCl}$ and $\mathrm{NaOH}$ solution. The results in Figure $4 \mathrm{~d}$ implied that the adsorption capacity is greatly depended on $\mathrm{pH}$ value variation, where at low $\mathrm{pH}$ values $(2-4)$, low qe values were obtained and that were attributed to the protonation surface of the adsorbent, indicating a high effect of protonic competition. Above $\mathrm{pH}=4$, the adsorption capacity increased progressively with an inflection point at ranges of $\mathrm{pH} 6$, where the $\mathrm{pKa}$ value of the majority of carboxylic acids, indicating the saponification of the carboxylic acid functions, and therefore the activation of active sites in the form of carboxylate functions. At this point, the maximum qe value was reached and it did not show a significant value change of qe $\left(2000-2150 \mathrm{mg} \cdot \mathrm{g}^{-1}\right)$.

To confirm the suggestions previously proposed, the zeta potential of swollen gel at different solution $\mathrm{pH}$ was investigated. The results, shown in Figure 4c, indicate that HECEDTA hydrogel was characterized by PZC corresponding to an isoelectric point of zeta potential at $\mathrm{pH}=3.42$, where the surface of the adsorbent was neutral and no characteristic 

adsorption occurred. Considering the typical crosslinking agent and its specificity, EDTA is a hyxaprotonic system representing a distinct proton distribution as a function of $\mathrm{pH}$. The first two acidities of EDTA are anchored to the polymeric chain, which explains its positive behavior of zeta potential, and that is due to the protonation of the amine forms into ammonium. Therefore, the increase in $\mathrm{pH}$ initiated the release of the other two acidities that neutralize the ammonium charge to the PZC. Beyond that, the adsorption capacity continues to increase, indicating the activation of the active carboxylic sites, reaching $1653 \mathrm{mg} . \mathrm{g}^{-1}$ and $1923 \mathrm{mg} \cdot \mathrm{g}^{-1}$ at $\mathrm{pH}$ values of 7 to 8 . At this stage of $\mathrm{pH}$ values, the contribution of first structural amine (pKa5 $=6.13$ ) of EDTA to the adsorption mechanism is suggested. This zone is characterized by a strong decrease in zeta potential to a value close to $-30 \mathrm{mV}$, which indicates the predominance of electrostatic interactions in the adsorption mechanism, as well as the carriers of the free doublets, in particular the amine and alcohol functions via sharing of their electronic densities. Subsequently, the second structural amine (pKa6 = 10.37) shows practically no activity (weak increase of qe which reaches $2180 \mathrm{mg} \cdot \mathrm{g}^{-1}$ at $\mathrm{pH}=11$ ), this is due probably to the high alkalinity of the solution where the competitiveness between hydroxide ions and active sites for MB is widely considered.

\section{Adsorption isotherms}

The modeling of adsorption isotherms were widely explored to elucidate the adsorbateadsorbent interactions, in particular to the interpretation of the concentration effect on the dyes adsorption efficiency on solid supports in solution. However, Langmuir, Freundlich, Temkin and Elovich are commonly used isotherm models describing the adsorption phenomenon to understand adsorbate-adsorbent interactions. In the Langmuir isothermal model, the adsorbed molecule is located on a well-defined and specific site of the adsorbent material (localized adsorption), and each site is only capable of binding to one adsorbatemolecule. The adsorption energy distribution of all adsorption sites is identical and independent of the adjacent adsorbed molecules (homogeneous surface and no adsorbateadsorbate interaction) (Langmuir 1918). Equation 11 gives the linear form of the Langmuir isotherm model.

$$
\frac{C_{e}}{q_{e}}=\frac{1}{k_{l} q_{m}}+\frac{C_{e}}{q_{m}}
$$


$471 \mathrm{C}_{\mathrm{e}}$ is the concentration of the MB aqueous solution of at equilibrium $\left(\mathrm{mg}^{-\mathrm{g}^{-1}}\right)$, qe is the adsorption capacity at equilibrium $\left(\mathrm{mg} \cdot \mathrm{g}^{-1}\right) . k_{l}$ is the Langmuir equilibrium constant that indicates the interaction level between the adsorbed molecules and the adsorbent surface, and $\mathrm{q}_{\mathrm{m}}$ is the maximum adsorption efficiency $\left(\mathrm{mg}_{\mathrm{g}} \mathrm{g}^{-1}\right)$. The separation factor is a very useful and characteristic factor of the Langmuir model $\left(R_{l}=1 /\left(1+K_{l} C_{0}\right)\right.$, the value of $R_{l}>1$ indicates that the adsorption is unfavorable, if $0<R_{l}<1$ the adsorption is favorable while the zero value of $R_{l}$ indicates that the adsorption is irreversible.

The relationship of classical isothermal Freundlich model is interpreted and proposed first by Saussure, and later popularized by Freundlich (Freundlich 1907). However, the linear form of power function (Eq. 12) describing the Freundlich isotherm model is commonly considered an empirical proposition, which gives an excellent description of the experimental isotherms obtained for solution phase adsorption (Weber Jr, Voice et al. 1983). In order to establish a theoretical basis linking the adsorption capacity and the physicochemical or/and molecular properties of adsorbent-adsorbate system, the Freundlich model has excited several lines of research. While, finding a theoretical description and introducing new concepts made the objective, especially order of fractal reaction (Skopp 2009), multilayer adsorption (Halsey 1948) and heterogeneity of the binding energy (Deliyanni, Peleka et al. 2007) and the surface potential (Sips 1948).

$$
\ln q_{e}=\ln K_{f}+\frac{1}{n} \ln C_{e}
$$

Recently, $\mathrm{Na}$ has shown, based on the Gibbsian interpretation of thermodynamics describing the Freundlich isotherm, that the solution phase adsorption is mainly controlled by the capillary effect of surface tension, and therefore the adsorption capacity can be quantitatively related to the molecular properties of adsorbate. In addition, analyzing the experimental values of $1 / \mathrm{n}$ (adsorption intensity, indicates the adsorbate affinity towards the adsorbent) and $\mathrm{K}_{\mathrm{f}}$ (Freundlich equilibrium constant) reported in the literature (Abe, Hayashi et al. 1982, Xia and Ball 1999), Na demonstrated the linear correlation between the inverse of the Freundlich power, n, and the molecular size of the adsorbate. Hence, the linear correlation between the Freundlich power and the logarithm of the equilibrium constant was discovered, revealing the existence of an isocapacity concentration (ICC) for the adsorption ( $\mathrm{Na} \mathrm{2020).}$ 

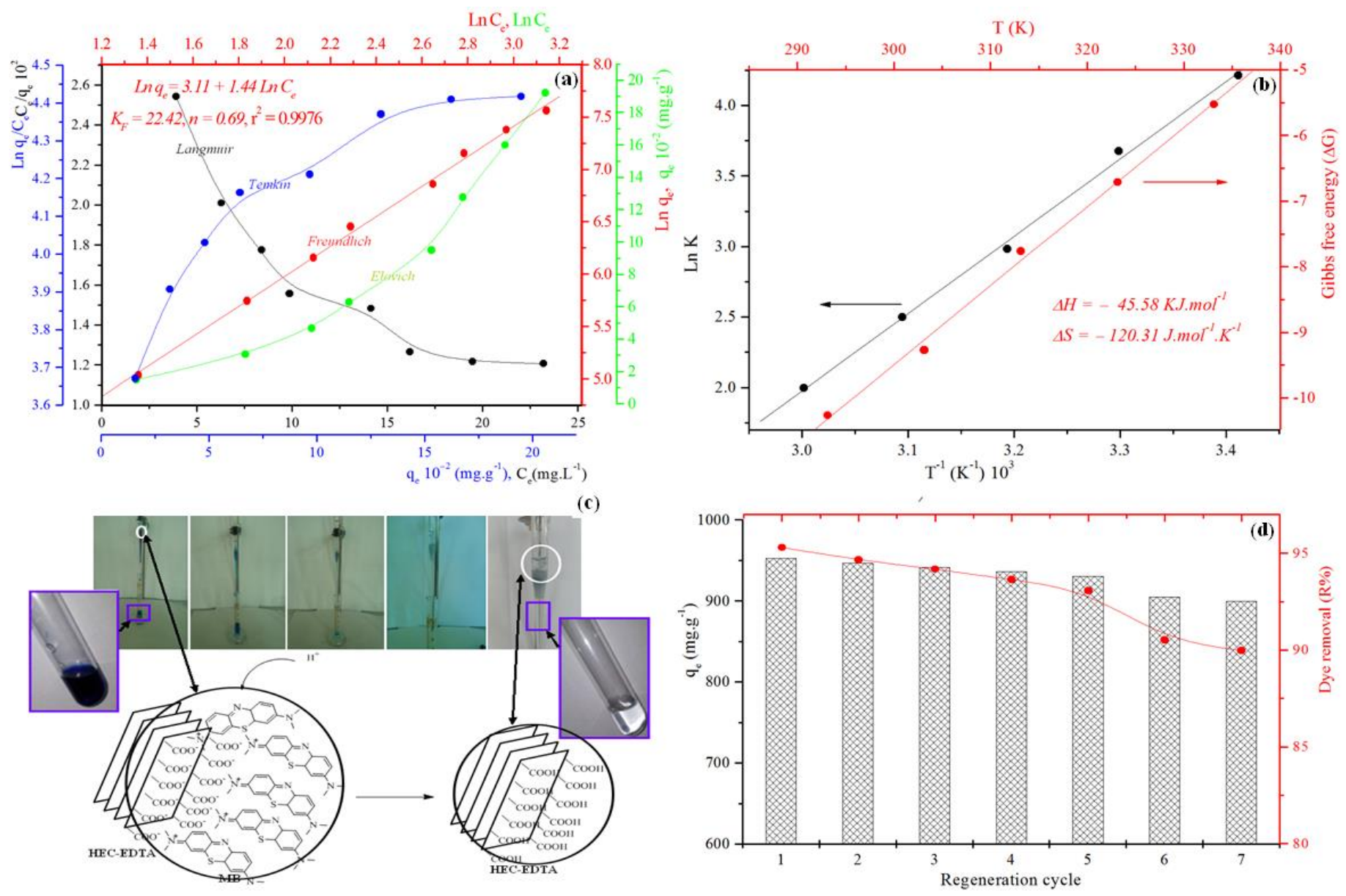

501

502

503

504

505

506

507

508

509

510

511

512

513

514

Fig. 5: (a) The experimental results of adsorption of MB on HEC-EDTA illustrated according to theoretical models (Langmuir, Freundlich, Temkin and Elovich), (b) variation of $\operatorname{lnK}$ and $\Delta \mathrm{G}$ against $1 / \mathrm{T}$ and $\mathrm{T}$, (c) Illustration of the regenerability steeps of HEC-EDTA and (d) variation of adsorption and dye removal capacities against regenerability cycle number

Temkin assumes that the heat of adsorption of all molecules in the cover layer decreases linearly with the degree of coverage [ref], this variation may be linked to side interactions between adsorbed molecules (adsorbent-adsorbate interactions) [ref]. However, the Temkin adsorption isotherm is characterized by a uniform distribution of surface binding energies (Kavitha and Namasivayam 2007). The Temkin isotherm is expressed by the equation 13, where, $\mathrm{q}_{\mathrm{e}}$ is the equilibrium adsorption efficiency $\left(\mathrm{mg} \cdot \mathrm{g}^{-1}\right), \mathrm{C}_{\mathrm{e}}$ is the equilibrium adsorbate concentration $\left(\mathrm{mg} \cdot \mathrm{L}^{-1}\right), \mathrm{R}$ is the universal gas constant $\left(\mathrm{J} \cdot \mathrm{mol}^{-1} \cdot \mathrm{K}^{-1}\right)$, T is the temperature $(\mathrm{K})$, $\mathrm{b}$ is the adsorption energy dependence constant and $\mathrm{Kt}$ is the equilibrium constant $\left(\mathrm{L} \cdot \mathrm{mg}^{-1}\right)$. 
Elovich model differs from that of Langmuir regarding the evolution of adsorption sites, where the density of available sites varies during adsorption, which implies adsorption in several layers (Hadj Salah 2012). The Elovich isotherm is expressed by the equation 14, where $\mathrm{q}_{\mathrm{m}}\left(\mathrm{mg} \cdot \mathrm{g}^{-1}\right)$ is the maximum adsorption capacity and $\mathrm{K}_{\mathrm{e}}$ is the Elovich constant $\left(\mathrm{mg}^{-1}\right)$.

$$
\ln \frac{q_{e}}{C_{e}}=\frac{q_{e}}{q_{m}}+\ln \left(k_{e} q_{m}\right)
$$

Figure 5a illustrates the experimental isothermal results of MB adsorption on HEC-EDTA, fitted according to the theoretical models of Langmuir, Freundlich, Temkin and Elovich. However, a strong correlation was observed for the Freundlich isotherm model, indicating its validity with a high coefficient of determination value $\left(r^{2}=0.9976\right)$, that is an indication of the reliability of the data and a good degree of reproducibility. This great correlation in a strong indication of the heterogeneity of active surface of material, and the MB adsorption was carried out in multilayer process. This result is in good agreement with the proposed structure where the presence of the different adsorbent sites with heterogenic reactivity in nature. Furthermore, in the crosslinking reaction conditions of HEC by EDTA, especially the value of the average functionality of crosslinking system $(f=1.75)$, is highly probable to suggest the formation of a two-dimensional network with different suggested active sites. In particular, the carboxylic functions (-COO-), the amines $(-\mathrm{N}<)$ and alcohols $(-\mathrm{OH})$ functions can interact by their free electronic-doublets as negative charges liable to create electrostatic bonds with the MB (Wang, Zhao et al. 2018, Ning, Zhang et al. 2021).

The Freundlich constants $\left(K_{f}=22.42 \mathrm{mg} \cdot \mathrm{g}^{-1}\right)$ which is a measure of the degree of adsorption and the exponent of non-linearity $(1 / n=1.44)$ can be determined from the slope and intercept of the $\ln q e=f(\ln C e)$ plot (linear red curve on Fig. 5a). However, the high value of $K_{f}$ suggests a high degree of heterogeneity (Somera, Cuazon et al. 2019), where to interpret the value of $1 / \mathrm{n}$ found in this work, it is important to highlight some efforts discussing the relationship between this constant and the mechanism of adsorption process. Therefore, the value 1/n derived from the Freundlich equation serves to describe the linearity of adsorption, or alternatively the degree of curvature of the isotherms described in the concentration range tested. In a nonlinear mode, the plot is linear for up to $50 \% \max$ saturation and then becomes nonlinear. Although the Freundlich equation provides important information regarding sorption of particles, but it has limited by the empirical aspect and its validity only up to a certain concentrations, above which it becomes nonlinear (K.Singh 
2016). However, the Freundlich model linearity has often been attributed to the unit value of the adsorption intensity $(n=1)$. Whereas, the non-linearity was associated with the hydrophobic behavior and to the hydrophobicity degree of the adsorbate molecules, where the adsorption process is controlled by the solubility level (ref). A unit value of $1 / \mathrm{n}$ was assigned to the homogeneous distribution of adsorbent sites, involving a type $\mathrm{C}$ isothermal distribution. While, values ranging from 0.7 to 1.0 showed a decrease in adsorption capacity with increasing of the concentration of the adsorbate molecules, which corresponds to the L-type isotherm profile, where much curved isotherms were encountered for $1 / \mathrm{n}$ values less than 0.7 .

Unusually, values greater than $1(1 / n>1)$ have been the subject of scientific debate with many gray areas about their meaning, several interpretations of which have been surmounted to the surface. Some authors have linked the small value of $n$ to the competitive effect, at low concentrations, between the different constituents of the adsorbate system or to solvent competition. On the light of this, Wu et al. have shown that systems anionic with the law competitive solute concentrations show similar $n$ values to that of the single solute $(n=0.33<$ 1), this finding suggests that the competitive effect is insignificant when are added in low concentrations (Wu, Lo et al. 2000, Wu, Kuo et al. 2002). A comparison study, performed by $W u$ et al., of the $\mathrm{n}$ values in single solute system with that in binary solute system, showed that a more significant competitive effect results in a higher $\mathrm{n}$ value but a lower $\mathrm{K}$ value $(W u$, Kuo et al. 2002). In addition, the same results were observed in the case of competitive adsorption with a Freundlich isotherm or in the case of heavy metals (Park, Ok et al. 2016, Zhang, Wei et al. 2016, Wang, Liu et al. 2018), or organic matter on solid supports (Yu, Wang et al. 2016, Conde-Cid, Ferreira-Coelho et al. 2019, Wang, Wang et al. 2019, Conde-Cid, Fernández-Sanjurjo et al. 2020). Moreover, Dada et al. considered the 1/n Freundlich value as an indicating parameter of the surface heterogeneity degree, where small values of $1 / \mathrm{n}$ indicating that a large level of heterogeneity is expected (Dada, Olalekan et al. 2012). Further on, Senthil Kumar et al. linked the value $\mathrm{n}<1$ to the chemical nature of the adsorption process, while $n>1$ means that a physical process nature of MB dye adsorption onto Sulfuric Acid Treated Orange Peel (Senthil Kumar, Fernando et al. 2014). However, according to Mohan et al., 1/n above one indicates a cooperative adsorption process (Mohan and Karthikeyan 1997, Dada, Olalekan et al. 2012), and is an adsorption validity index if $\mathrm{n}$ is between one and ten (Goldberg 2005). At $1 / \mathrm{n}<0.1$, the adsorption isotherm approaches irreversible isotherm (Worch 2012, Saadi, Saadi et al. 2015), etc. 
Faced to this ambiguity and the absence of an interpretation based on acceptable theoretical usefulness of this famous model, almost all of the authors agree that the value of $1 / \mathrm{n}$ can classify adsorption isotherms as concave $(1 / n>1)$ and convex $(1 / n<1)$ functions. The first one showed the direct proportionality of sorption energy to the surface concentration, where the convex demonstrated that the adsorption energy is inversely proportional to the surface concentration (Can, Ömür et al. 2016). Therefore, the obtained value for $1 / \mathrm{n}$ (1.44), in this work, is greater than unity thus, indicating a heterogonous sorption energy distribution.

In addition, S-type adsorption, according to the classification of Giles et al. for solution phase adsorption isotherms (Giles, Smith et al. 1974), is most considered to adsorbing adsorbate containing a polar functional group on adsorbent hydrogels. This was observed even for high values of 1/n, which can reach about ten (between 2 and 12) (Gu and Zhu 1990, Yurdakoç, Seki et al. 2005, Khandelwal, Narayanan et al. 2020). This correspondence can be attributed, at low concentrations, to the difference between the force of diffusion - swelling of solvent versus the force of concentration gradient and mass transfer of solute (Kaşgöz and Durmus 2008, Narayanan, Nethran et al. 2014, Bai, Zhang et al. 2016, Du and Piao 2018, Saraydın, Işıkver et al. 2018).

\section{Thermodynamic study and regenerability}

The effect of temperature on the adsorption capacity was studied within the temperature range between 20 and $60{ }^{\circ} \mathrm{C}\left(\mathrm{C} 0=300 \mathrm{mg} \cdot \mathrm{L}^{-1}\right.$, contact time $=30 \mathrm{~min}$, pH8 and $\left.0.3 \mathrm{~g} . \mathrm{L}^{-1}\right)$. However, the linear curves representing the thermal profiles of the adsorption equilibrium constant $(\ln K=f(1 / T))$ and of the Gibbsian energy variation $(\Delta \mathrm{G}=\mathrm{f}(\mathrm{T}))$ are shown on Figure 5b. As can be seen that, increasing temperature was inversely influenced the evolution of $L n \mathrm{~K}$, which indicates the increase in the rate constant of the reverse reaction of adsorption, where the adsorption equilibrium moves in the opposite direction. This profile is accompanied by a similar decrease in the adsorption capacity, indicating the physisorption nature of adsorption process, where the stability of the physical adsorbent-adsorbate bonds is low compared to the thermal energy supplied to the system, and consequently, the breakdown and shift of equilibrium towards favoring desorption. Similarly, the increase in the Gibbs energy $(\Delta \mathrm{G})$ value of the of the adsorption reaction, increasing temperature (Figure $5 \mathrm{~b}$ ), is a strong indication of the physical aspect of the adsorption process. This behavior of free energy confirms the previous result and justifies the changes in the equilibrium constant with 
temperature. The Gibbs energy change of the adsorption reaction was estimated from Equation 15:

$$
\Delta G=-R T \ln K
$$

Where $\Delta \mathrm{G}$ is the variation of free energy $\left(\mathrm{KJ} \mathrm{mol}^{-1}\right), \mathrm{R}$ is the universal gas constant. $\mathrm{T}$ is the temperature $(\mathrm{K})$ and $K$ is the equilibrium constant. The values of the enthalpy $(\Delta \mathrm{H})$ and the entropy $(\Delta \mathrm{S})$ can be calculated from the Van'tHoff Equation (Eq. 16):

$$
\ln K=-\frac{\Delta H}{R T}+\frac{\Delta S}{R}
$$

The thermodynamic parameters of the adsorption, $\Delta H$ and $\Delta S$, can be determined by plotting $\operatorname{LnK}=f(1 / T)$. The negative values of $\Delta G$ confirm the spontaneous behavior of the adsorption process, while negative enthalpy value of $\Delta H\left(-45.58 \mathrm{KJ}_{\mathrm{mol}}{ }^{-1}\right)$ shows the exothermic nature of the reaction. In addition, the negative entropy value of $\Delta S(-120.31$ $J . \mathrm{mol}^{-1} . \mathrm{k}^{-1}$ ) indicates an increase in the molecular order and a significant decrease in the degree of freedom of the solute molecules $(M B)$, when fleeting from the solution to the adsorbent surface connection. The apparent activation energy value $(E a / R)$ was estimated from the experimental data, using the modified Arrhenius equation related to the surface coverage $(\theta)$ and the sticking probability, that quantifies the potential of an adsorbate to remain on the adsorbent indefinitely (Horsfall Jnr and Spiff 2005, Aljeboree, Alkaim et al. 2015, Thabet and Ismaiel 2016, Labidi, Salaberria et al. 2019). However, the surface coverage was calculated according to the following relation: $\theta=1-\mathrm{C}_{\mathrm{e}} / \mathrm{C}_{0}$, where $C_{0}$ and $C_{e}$ are initial and equilibrium MB concentrations, respectively. Yet, plotting $\ln (1-\theta)$ against $1 / T$ gives a linear plot with a slope of $E a / R$, which $E a / R$ value was found to be $-4.7 \mathrm{KJ}_{\text {.g. }} \mathrm{mol}^{-1}$. The negative value of $E a$ confirms that the MB adsorption process is exothermic in nature, and indicates that lower temperatures were favorable for the MB removal by adsorption using HEC-EDTA adsorbent. Therefore, these results complement the previous ones and confirm that the process of sorption of MB is physisorption. In addition, the low values of $E a$ suggest that adsorption is a diffusion-controlled process.

Even with their adsorption efficiency, adsorbents must be inexpensive, regenerated, and present a green approach, which encourages their use at the industrial level. It is therefore desirable to have economically viable methods for removing cationic dyes, in particular by adsorbents based on environmentally and friendly raw materials. In this context, HEC-EDTA 
hydrogel have an exceptionally high adsorption capacity for MB. The procedure of recovering the organic dyes, during the adsorbent regeneration step, is easily accomplished by eluting the gelatinous mass with adequate $0.1 \mathrm{M}$ aqueous acid solution (Hu, Liang et al. 2018, Wang, Zhang et al. 2020, Ning, Zhang et al. 2021). In this paper, the study of the regenerability and reusability of elaborated HEC based hydrogel, was carried out for $0.5 \mathrm{~g}$ of HEC-EDTA-BM (qe $950 \mathrm{mg} . \mathrm{g}-1$ ) in a $10 \mathrm{~mL}$ column, eluted with $0.1 \mathrm{M}$ aqueous $\mathrm{HCl}$ solution (Fig. 5c). Figure $5 \mathrm{c}$ shows that the upward flow of acid causes discoloration of the adsorbent, while the solution collected at the outlet of the column has become colorless after adding a volume of acid that does not exceed $10 \mathrm{~mL}$. Regeneration results from the release of $\mathrm{BM}$ under the action of the acid, which causes the protonation of the carboxylate and amino functions on the surface of the HEC-EDTA adsorbent, and consequently, eliminates the electrostatic interactions between BM and HEC -EDTA.

Reusability is one of the important properties of the adsorbent for practical application, especially to dyes removal in wastewater treatment. The adsorption-desorption flow chart and adsorption-desorption cycles are exhibited in Figure 5d. As shown in Fig 5c, after five adsorption-desorption cycles, the adsorption capacity still maintained at around of the original adsorption capacity. Hence, a slight decrease after five consecutive adsorptiondesorption cycles (for 6th and 7th cycle), but the dye removal still exceeded $90 \%$ to the initial adsorption. High adsorption efficiency and long life cycle of HEC-HEC hydrogel, provides promising material as ecofriendly regenerable adsorbent with high-performance and excellent practical value for industrial applications.

\section{Theoretical and Computational Study}

MD simulations for the analyzed structures were conducted with the Adsorption Locator module imbedded in Materials Studio2017 software (Amrhar, Berisha et al. 2021). Force field parameterizations were calculated and optimized using COMPASS II (Biabangard, Nazari et al. 2021). The considered structures for this work were: i) Periodic HEC-EDTA system consists of HEC oligomers containing 6 monomers grafted by EDTA according to the experimental discussed results above (degree of substitution $(D S)$ and degree, crosslinking (Dc \%) and two conjugated bases of carboxylic groups by EDTA, and ii) Cationic MB ions optimized using DFT methods (Pelalak, Soltani et al. 2021). However, the initial charges implemented were Hirshfeld charges. The charge partitioning by Hirshfeld method shows that 
$671 \mathrm{~S}$ atom has a positive charge of $0.1504 \mathrm{e}$, and $\mathrm{N}$ has a negative charge of $0.1471 \mathrm{e}$ (Li, Zhang

672

673

674

675

676

677

678

679

680

681

et al. 2018).

Adsorption simulation was carried out on two stages, adsorption of $12 \mathrm{MB}+$ on the surface of HEC - EDTA layer of 6 monomers, followed by MD simulations to achieve the optimal results. MD simulations have been conducted as NPT ensemble giving the experimental conditions (Guo, Zhang et al. 2020). Temperature and pressure were controlled using the Nose-Hoover and Berendsen method respectively, with all simulations performed at $298.15 \mathrm{~K}$ and at 1 bar. The motion equations were integrated using the velocity verlet integrator method with a time phase of 1 fs. Lennard-Jones encounters were handled with possible $15 \AA$ cut-offs and Periodic boundary conditions have been applied in all directions, and 10 ps long MD Simulations have been used for the studied systems.

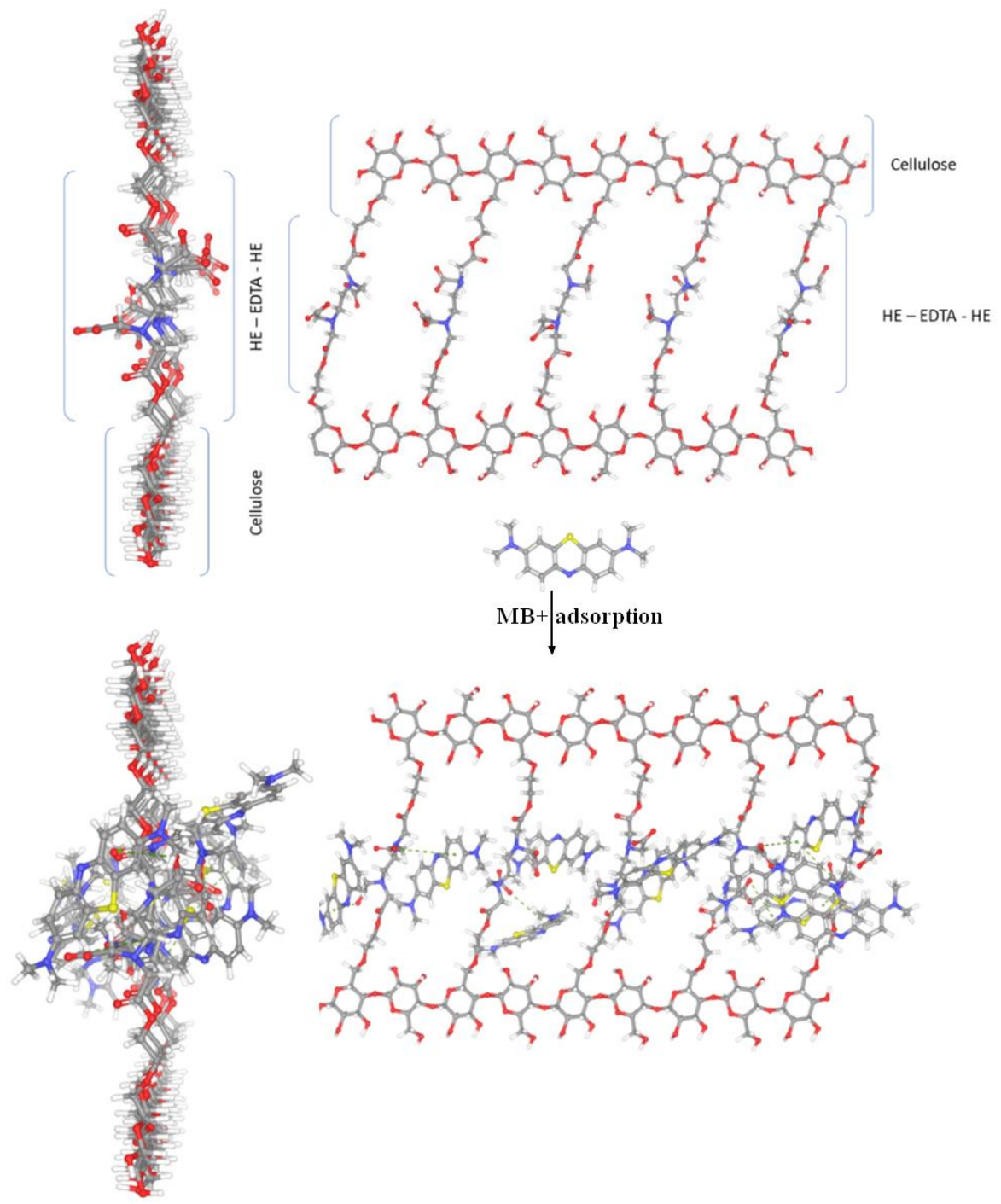


The molecular structures of $\mathrm{MB}+$ and HEC-EDTA were examine in terms of intermolecular Non-covalent interactions including Pi-Pi interactions, anion-Pi interactions and electrostatic interactions, and sub-structural molecular clusters. However, MD simulations results showed that the adsorption process was better described by non-covalent interactions between methylene blue and EDTA on the adsorption, especially the electrostatic collisions which given the possibility to create regioselective clusters around EDTAcarboxylates (Stîngă, Băran et al. 2021). At first, the results of MD simulation reveal the tendency of $\mathrm{MB}+$ to be adsorbed on EDTA surface, as expected this is due to electrostatically interaction between cationic MB ions and anionic EDTA-carboxylate groups (Fig. 6). Electrostatically interactions (between $\mathrm{MB}+$ and $\mathrm{O}-$ ) and $\mathrm{Pi}$-cations (between aromatic rings and MB-) led to the formation of the major molecular clusters. On the other hand, the Pi-Pi interactions (between Phenyl groups themselves and between Phenyl groups and carbonyl oxygen) and the Pi-cation interactions (between delocalized $\mathrm{MB}+$ and carboxylic conjugate groups) sustain sub structural clusters (Fig. 2, 3) (Khalaf, Hamed et al. 2021).

\section{Molecular structure and cluster configurations}

Molecular dynamics simulations indicated the formation of specific configurations of MBEDTA clusters on specific HEC-EDTA surface areas. The region selectivity of MB+ adsorption observed on Fig. 1 is due to non-covalent interactions discussed above, where the repulsive forces between grafted EDTA $^{2-}$ give reason to the apparition of new structural orientations and configurations. These steric arrangement in the new chemical environment induced a new redistribution of bond strengths, where the formation of cavities (Fig. 7a) allowing the $\mathrm{MB}+$ absorption in several geometric possibilities (clusters), which explains the high adsorption capacity of HEC-EDTA material to cationic dyes. Yet, the orientation of $\mathrm{MB}+$ was finding selective (i.e. Phenyl rings toward O- by anion - Pi interaction) (Fig. 7). 


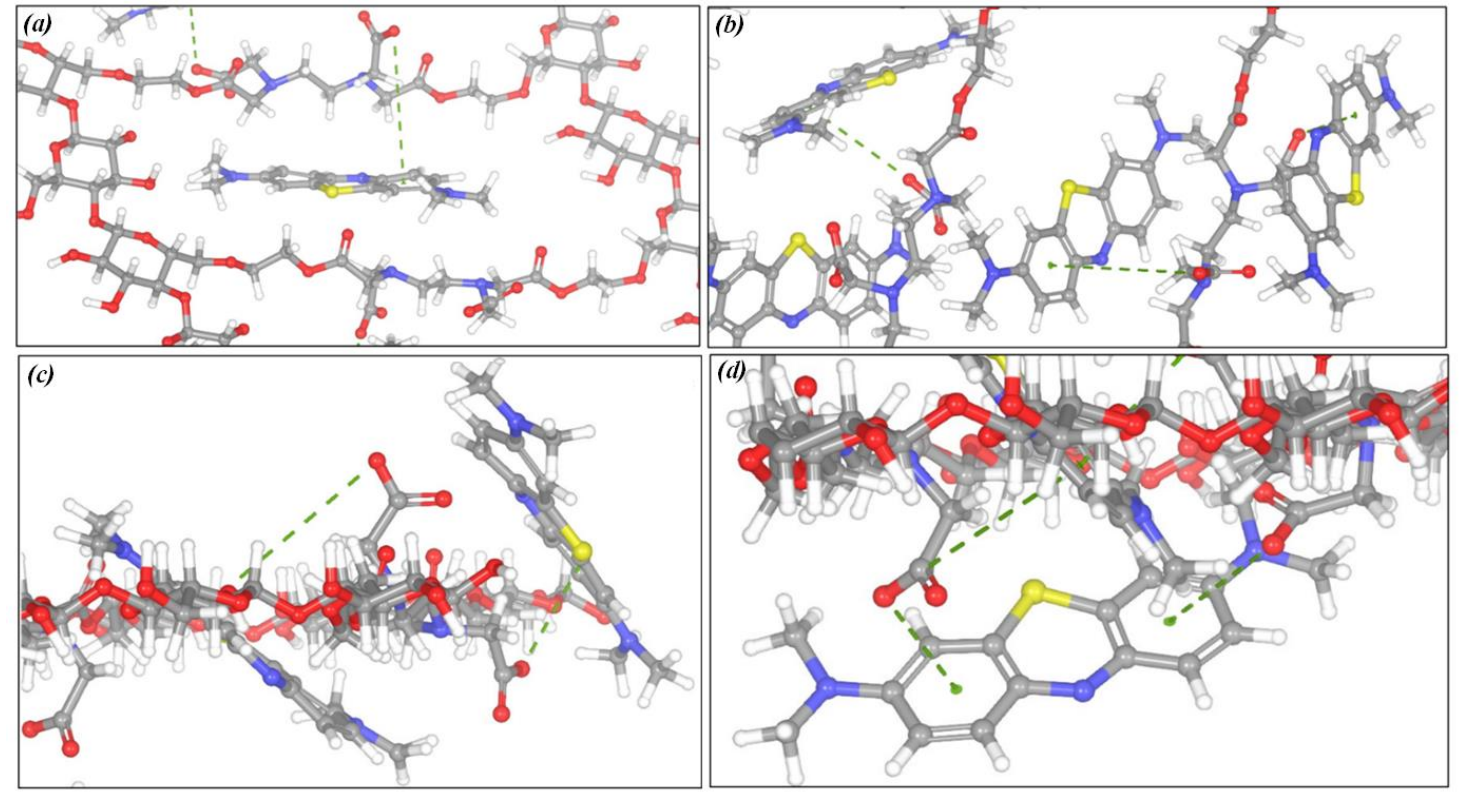

Fig.7: Submolecular clusters MB-EDTA interactions (Dashed lines: Non-covalent interactions).

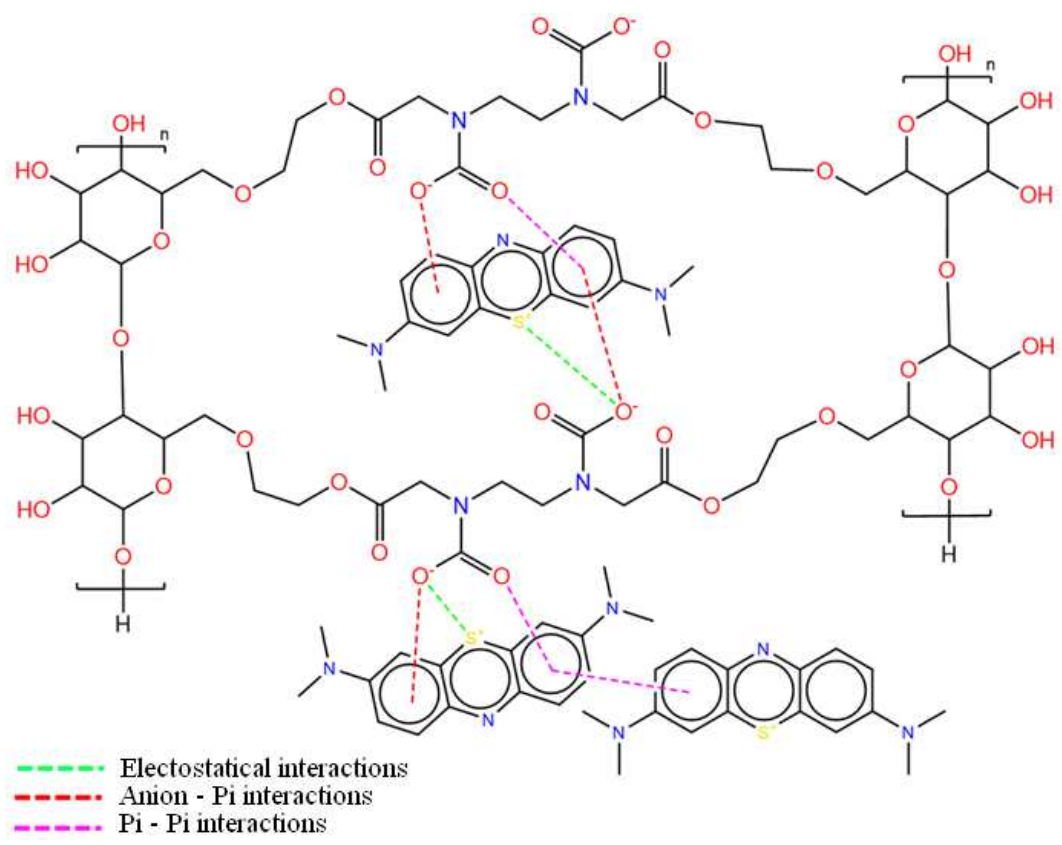

Fig. 8: Proposal MB adsorption mechanism on HEC-EDTA

In addition, the contribution of repulsive forces (i.e. repulsive forces, cation-Pi and Pi-Pi interaction) to the formation of $\mathrm{MB}+$ clusters is strongly suggested. However, the Pi-Pi interaction of phenyl rings leads to ring stacking, consequently inducing the formation of $\mathrm{MB}$ + aggregates. With regard to the excess repulsive charges, this is compensated by a negative EDTA charge. Thus, the results correlate with experimental evidence and explained them in 
terms of molecular adsorption, and in good agreement with thus recently published in the literature (Mohammed, Lian et al. 2021) (Fig. 8).

\section{Conclusion}

New EDTA crosslinked cellulose derivative based material was successfully elaborated, and investigated as new green and efficient adsorbent-hydrogel to cationic dyes removal. In this paper, the synthesis of HEC-EDTA at high advanced crosslinking degree (up to $92 \%$ ), was cried out using DAEDT and DMAP as acyl transfer agent, where the lamellar morphology (2D-dimensional microstructure) was suggested from the average functionality of the reaction system. The proposal structures were confirmed using structural analyzes (FTIR and 13C CP/MAS NMR). The adsorption process was better described by pseudo-secondorder kinetic. However, the study of thermodynamic parameters exhibited a negative effect of temperature indicating a physical adsorption process. In addition, the Freundlich model revealed a strong correlation to the experimental results, which is a solid indication to energetic heterogeneity of the surface active sites. Molecular dynamics simulations were investigated to confirm the experimental results and the good agreement was shown. The high adsorption efficient of HEC-EDTA to cationic dyes was attributed, basing on the MDs results, to the formation of specific configurations of MB-EDTA clusters, where the non-covalent interactions is predominant. In addition, the repulsive forces between MB entities and between MB and grafted $\mathrm{EDTA}^{2-}$ give reason to the apparition of new structural orientations and configurations (electrostatic cavities), thus increase the adsorption efficiency.

\section{Acknowledgements}

We thank greatly the anonymous reviewers for their careful review and valuable suggestions on the manuscript. The authors are thankful to the Head of Oujda's chemistry department, Prof. Abdelmonaem TALHAOUI, for providing all the facilities and subsidies necessary to carry out the research work of this article. Our warm thanks are addressed to Prof. Gharibi EL KHADIR, Director of the Solid Mineral Solid Chemistry Laboratory Oujda, for his sincere and persistent contributions and devoted cooperation.

\section{References}

Abe, I., K. Hayashi, T. Hirashima and M. Kitagawa (1982). "Relationship between the Freundlich adsorption constants $\mathrm{K}$ and 1/N hydrophobic adsorption." Journal of the American Chemical Society 104(23): 64526453. 
Al-Kdasi, A., A. Idris, K. Saed and C. T. Guan (2004). "Treatment of textile wastewater by advanced oxidation processes - a review." Global nest: the Int. J 6(3): 222-230.

Aljeboree, A. M., A. F. Alkaim and A. H. Al-Dujaili (2015). "Adsorption isotherm, kinetic modeling and thermodynamics of crystal violet dye on coconut husk-based activated carbon." Desalination and Water Treatment 53(13): 3656-3667.

Amrhar, O., A. Berisha, L. El Gana, H. Nassali and M. S. Elyoubi (2021). "Removal of methylene blue dye by adsorption onto Natural Muscovite Clay: experimental, theoretical and computational investigation." International Journal of Environmental Analytical Chemistry: 1-26.

Andreozzi, R., V. Caprio, A. Insola and R. Marotta (1999). "Advanced oxidation processes (AOP) for water purification and recovery." Catalysis today 53(1): 51-59.

Bai, H., Q. Zhang, T. He, G. Zheng, G. Zhang, L. Zheng and S. Ma (2016). "Adsorption dynamics, diffusion and isotherm models of poly (NIPAm/LMSH) nanocomposite hydrogels for the removal of anionic dye Amaranth from an aqueous solution." Applied Clay Science 124: 157-166.

Barclay, S. and C. Buckley (2000). "Waste Minimization Guide for the Textile Industry." A step towards cleaner production 1.

Barka, N., S. Qourzal, A. Assabbane, A. Nounah and A.-i. Yhya (2008). "Adsorption of Disperse Blue SBL dye by synthesized poorly crystalline hydroxyapatite." Journal of Environmental Sciences 20(10): 1268-1272.

Beer, R., M. A. Baumann and A. M. Kielbassa (2006). Endodontia: texto e atlas. Endodontia: texto e atlas: 246246.

Biabangard, F., H. Nazari and R. Arefinia (2021). "Effect of pH on the electrochemical properties of polyaniline nanoparticle suspension in strongly acidic solution: an experimental and theoretical study." Journal of Solid State Electrochemistry 25(3): 881-893.

Bolotin, P., S. Baranovsky and M. Evstigneev (2006). "Spectrophotometric investigation of the heteroassociation of Caffeine and thiazine dye in aqueous solution." Spectrochimica Acta Part A: Molecular and Biomolecular Spectroscopy 64(3): 693-697.

Calcagnile, P., T. Sibillano, C. Giannini, A. Sannino and C. Demitri (2019). "Biodegradable poly (lactic acid)/cellulose-based superabsorbent hydrogel composite material as water and fertilizer reservoir in agricultural applications." Journal of Applied Polymer Science 136(21): 47546.

Can, N., B. C. Ömür and A. Altındal (2016). "Modeling of heavy metal ion adsorption isotherms onto metallophthalocyanine film." Sensors and Actuators B: Chemical 237: 953-961.

Cao, Y.-L., Z.-H. Pan, Q.-X. Shi and J.-Y. Yu (2018). "Modification of chitin with high adsorption capacity for methylene blue removal." International journal of biological macromolecules 114: 392-399.

Capretta, A., R. B. Maharajh and R. A. Bell (1995). "Synthesis and characterization of cyclomaltoheptaosebased metal chelants as probes for intestinal permeability." Carbohydrate Research 267(1): 49-63.

Cenens, J. and R. Schoonheydt (1988). "Visible spectroscopy of methylene blue on hectorite, laponite B, and barasym in aqueous suspension." Clays and Clay Minerals 36(3): 214-224.

Cha, C.-J., D. R. Doerge and C. E. Cerniglia (2001). "Biotransformation of Malachite Green by the FungusCunninghamella elegans." Applied and environmental microbiology 67(9): 4358-4360.

Chaouf, S., S. El Barkany, I. Jilal, Y. El Ouardi, M. Abou-salama, M. Loutou, A. El-Houssaine, H. El-Ouarghi, A. El Idrissi and H. Amhamdi (2019). "Anionic reverse microemulsion grafting of acrylamide (AM) on HydroxyEthylCellulose (HEC): synthesis, characterization and application as new ecofriendly low-cost flocculant." Journal of Water Process Engineering 31: 100807.

Chergui, S. (2010). Dégradation des colorants textiles par procédés d'oxydation avancée basée sur la réaction de Fenton: application à la dépollution des rejets industriels.

Choudhury, P. R., S. Majumdar, G. C. Sahoo, S. Saha and P. Mondal (2018). "High pressure ultrafiltration $\mathrm{CuO} /$ hydroxyethyl cellulose composite ceramic membrane for separation of $\mathrm{Cr}$ (VI) and $\mathrm{Pb}$ (II) from contaminated water." Chemical Engineering Journal 336: 570-578.

Conde-Cid, M., M. J. Fernández-Sanjurjo, G. Ferreira-Coelho, D. Fernández-Calviño, M. Arias-Estevez, A. Núñez-Delgado and E. Álvarez-Rodríguez (2020). "Competitive adsorption and desorption of three tetracycline antibiotics on bio-sorbent materials in binary systems." Environmental Research 190: 110003.

Conde-Cid, M., G. Ferreira-Coelho, A. Núñez-Delgado, D. Fernández-Calviño, M. Arias-Estévez, E. ÁlvarezRodríguez and M. J. Fernández-Sanjurjo (2019). "Competitive adsorption of tetracycline, oxytetracycline and chlortetracycline on soils with different $\mathrm{pH}$ value and organic matter content." Environmental research 178: 108669.

Coryell, T. N. (2017). "Characterization of Cement Thickening Time Properties and Modeling of Thickening Time." MsT: 34

Crini, G., P. Badot, N. Morin-Crini and G. Torri (2007). "Wastewater treatment processes: a recent review of the available methods." Press universitaires de Franche-Comte (PUFC): 16-62. 
Culp, S., F. Beland, R. Heflich, R. Benson, L. Blankenship, P. Webb, P. Mellick, R. Trotter, S. Shelton and K. u. Greenlees (2002). "Mutagenicity and carcinogenicity in relation to DNA adduct formation in rats fed leucomalachite green." Mutation Research/Fundamental and Molecular Mechanisms of Mutagenesis 506: 55-63.

Dada, A., A. Olalekan, A. Olatunya and O. Dada (2012). "Langmuir, Freundlich, Temkin and DubininRadushkevich isotherms studies of equilibrium sorption of $\mathrm{Zn} 2+$ unto phosphoric acid modified rice husk." IOSR Journal of Applied Chemistry 3(1): 38-45.

Danel, V. (1999). Intoxications aiguës en réanimation, Wolters Kluwer France.

De Guzman, N. and M. D. L. Balela (2019). Atmospherically Stable Silver Nanowire/Hydroxyethyl Cellulose Films and their Application in Flexible Transparent Touch Screen. Key Engineering Materials, Trans Tech Publ.

Du, H. and M. Piao (2018). "Facile preparation of microscale hydrogel particles for high efficiency adsorption of bisphenol A from aqueous solution." Environmental Science and Pollution Research 25(28): 2856228571.

Dutta, K., S. Mukhopadhyay, S. Bhattacharjee and B. Chaudhuri (2001). "Chemical oxidation of methylene blue using a Fenton-like reaction." Journal of hazardous materials 84(1): 57-71.

Elbedwehy, A. M. and A. M. Atta (2020). "Novel Superadsorbent Highly Porous Hydrogel Based on Arabic Gum and Acrylamide Grafts for Fast and Efficient Methylene Blue Removal." Polymers 12(2): 338.

Freundlich, H. (1907). "Über die adsorption in lösungen." Zeitschrift für physikalische Chemie 57(1): 385-470.

Gbadamosi, S., A. Famuwagun and A. Nnamezie (2018). "Effects of Blanching with Chemical Preservatives on Functional and Antioxidant Properties of Fluted Pumpkin (Telferia occidentalis) Leaf." Nigerian Food Journal 36(1): 45-57.

Giles, C. H., D. Smith and A. Huitson (1974). "A general treatment and classification of the solute adsorption isotherm. I. Theoretical." Journal of colloid and interface science 47(3): 755-765.

Gobi, K., M. Mashitah and V. Vadivelu (2011). "Adsorptive removal of methylene blue using novel adsorbent from palm oil mill effluent waste activated sludge: equilibrium, thermodynamics and kinetic studies." Chemical engineering journal 171(3): 1246-1252.

Goldberg, S. (2005). "Equations and models describing adsorption processes in soils." Chemical processes in soils 8: 489-517.

Greene, J. C. and G. L. Baughman (1996). "Effects of 46 Dyes on Population Growth of Freshwater Green Alga Se/eksfrum capricornutum." Text. Chem. Color 28(4): 23-30.

$\mathrm{Gu}, \mathrm{T}$. and B.-Y. Zhu (1990). "The S-type isotherm equation for adsorption of nonionic surfactants at the silica gel-water interface." Colloids and surfaces 44: 81-87.

Guo, F., J. Zhang, J. Pei, B. Zhou, A. C. Falchetto and Z. Hu (2020). "Investigating the interaction behavior between asphalt binder and rubber in rubber asphalt by molecular dynamics simulation." Construction and Building Materials 252: 118956.

Hadj Salah, N. (2012). Etude de la dégradation photocatalytique de polluants organiques en présence de dioxyde de titane, en suspension aqueuse et en lit fixe, Grenoble.

Halsey, G. (1948). "Physical adsorption on non-uniform surfaces." The Journal of chemical physics 16(10): 931937.

Hämmer, M., A. Gassmann, A. Reller, H. von Seggern, O. Gutfleisch, R. Stauber and J. Zimmermann (2019). "Recyclable phosphor films: three water-soluble binder systems enabling the recovery of phosphor powders in white leds." Journal of Electronic Materials 48(4): 2294-2300.

Han, X., W. Wang and X. Ma (2011). "Adsorption characteristics of methylene blue onto low cost biomass material lotus leaf." Chemical Engineering Journal 171(1): 1-8.

Hasan, A., G. Waibhaw, V. Saxena and L. M. Pandey (2018). "Nano-biocomposite scaffolds of chitosan, carboxymethyl cellulose and silver nanoparticle modified cellulose nanowhiskers for bone tissue engineering applications." International journal of biological macromolecules 111: 923-934.

Hitz, H., W. Huber and R. Reed (1978). "Publication Sponsored by ETAD The Adsorption of Dyes on Activated Sludge." Journal of the Society of Dyers and Colourists 94(2): 71-76.

Horsfall Jnr, M. and A. I. Spiff (2005). "Effects of temperature on the sorption of $\mathrm{Pb} 2+$ and $\mathrm{Cd} 2+$ from aqueous solution by Caladium bicolor (Wild Cocoyam) biomass." Electronic Journal of Biotechnology 8(2): 4350.

Hu, T.-L. (1996). "Removal of reactive dyes from aqueous solution by different bacterial genera." Water science and technology 34(10): 89-95.

Hu, X.-S., R. Liang and G. Sun (2018). "Super-adsorbent hydrogel for removal of methylene blue dye from aqueous solution." Journal of Materials Chemistry A 6(36): 17612-17624.

Huang, F., L. Chen, H. Wang and Z. Yan (2010). "Analysis of the degradation mechanism of methylene blue by atmospheric pressure dielectric barrier discharge plasma." Chemical Engineering Journal 162(1): 250256. 
Huang, S., L. Wu, T. Li, D. Xu, X. Lin and C. Wu (2019). "Facile preparation of biomass lignin-based hydroxyethyl cellulose super-absorbent hydrogel for dye pollutant removal." International journal of biological macromolecules 137: 939-947.

Jilal, I., S. El-Barkany, Z. Bahari, O. Sundman, A. El-Idrissi, M. Abou-Salama, M. Loutou, E. Ablouh and H. Amhamdi (2019). "New benzyloxyethyl cellulose (BEC) crosslinked EDTA: synthesis, characterization and application for supramolecular self-assembling nanoencapsulation of $\mathrm{Pb}$ (II)." Materials Today: Proceedings 13: 909-919.

Jilal, I., S. El Barkany, Z. Bahari, O. Sundman, A. El Idrissi, M. Abou-Salama, A. Romane, C. Zannagui and H. Amhamdi (2018). "New quaternized cellulose based on hydroxyethyl cellulose (HEC) grafted EDTA: synthesis, characterization and application for $\mathrm{Pb}$ (II) and $\mathrm{Cu}$ (II) removal." Carbohydrate polymers $\mathbf{1 8 0}$ : 156-167.

Jilal, I., S. El Barkany, Z. Bahari, O. Sundman, A. El Idrissi, A. Salhi, M. Abou-Salama, M. Loutou and H. Amhamdi (2018). "Unconventional synthesis, characterization and theoretical study (HF and DFT computations) of new cellulosic copper complex: benzyloxyethyl cellulose copper (CuBEC)." Cellulose 25(8): 4375-4388.

Jin, T., C. D. Easton, H. Yin, M. de Vries and X. Hao (2018). "Triethylenetetramine/hydroxyethyl cellulosefunctionalized graphene oxide monoliths for the removal of copper and arsenate ions." Science and Technology of advanced MaTerialS 19(1): 381-395.

Júnior, O. K., L. V. A. Gurgel, R. P. de Freitas and L. F. Gil (2009). "Adsorption of Cu (II), Cd (II), and Pb (II) from aqueous single metal solutions by mercerized cellulose and mercerized sugarcane bagasse chemically modified with EDTA dianhydride (EDTAD)." Carbohydrate Polymers 77(3): 643-650.

K.Singh, A. (2016). "Engineered Nanoparticles

Structure, Properties and Mechanisms of Toxicity." Engineered Nanoparticles

Structure, Properties and Mechanisms of Toxicity: 343-450.

Kaşgöz, H. and A. Durmus (2008). "Dye removal by a novel hydrogel-clay nanocomposite with enhanced swelling properties." Polymers for Advanced Technologies 19(7): 838-845.

Kavitha, D. and C. Namasivayam (2007). "Experimental and kinetic studies on methylene blue adsorption by coir pith carbon." Bioresource Technology 98(1): 14-21.

Kellner-Rogers, J. S., J. K. Taylor, A. M. Masud, N. Aich and A. H. Pinto (2019). "Kinetic and thermodynamic study of methylene blue adsorption onto chitosan: insights about metachromasy occurrence on wastewater remediation." Energy, Ecology and Environment 4(3): 85-102.

Khalaf, B., O. Hamed, S. Jodeh, G. Hanbali, R. Bol, O. Dagdag and S. Samhan (2021). "Novel, EnvironmentFriendly Cellulose-Based Derivatives for Tetraconazole Removal from Aqueous Solution." Polymers 13(3): 450.

Khandelwal, A., N. Narayanan, E. Varghese and S. Gupta (2020). "Linear and nonlinear isotherm models and error analysis for the sorption of kresoxim-methyl in agricultural soils of India." Bulletin of environmental contamination and toxicology: 1-8.

Labidi, A., A. M. Salaberria, S. Fernandes, J. Labidi and M. Abderrabba (2019). "Functional chitosan derivative and chitin as decolorization materials for methylene blue and methyl orange from aqueous solution." Materials 12(3): 361.

Langmuir, I. (1918). "The adsorption of gases on plane surfaces of glass, mica and platinum." Journal of the American Chemical society 40(9): 1361-1403.

Li, H., Y. Lin, Y. Luo, P. Yu and L. Hou (2011). "Relating organic fouling of reverse osmosis membranes to adsorption during the reclamation of secondary effluents containing methylene blue and rhodamine B." Journal of hazardous materials 192(2): 490-499.

Li, M.-C., C. Mei, X. Xu, S. Lee and Q. Wu (2016). "Cationic surface modification of cellulose nanocrystals: Toward tailoring dispersion and interface in carboxymethyl cellulose films." Polymer 107: 200-210.

Li, Y., X. Zhang, D. Chen, S. Xiao and J. Tang (2018). "Adsorption behavior of COF2 and CF4 gas on the MoS2 monolayer doped with Ni: a first-principles study." Applied Surface Science 443: 274-279.

Liu, X., J. Tian, Y. Li, N. Sun, S. Mi, Y. Xie and Z. Chen (2019). "Enhanced dyes adsorption from wastewater via Fe3O4 nanoparticles functionalized activated carbon." Journal of hazardous materials 373: 397-407.

Liu, X., C. Wang, A. Wang, J. Qu, Y. Wen and B. Wei (2019). "Application of cellulose and cellulose nanofibers in oil exploration." Paper and Biomaterials 4(3): 69.

Luo, P., L. Liu, W. Xu, L. Fan and M. Nie (2018). "Preparation and characterization of aminated hyaluronic acid/oxidized hydroxyethyl cellulose hydrogel." Carbohydrate polymers 199: 170-177.

Ma, Y., X. Gong, C. Liao, X. Geng, C. Wang and F. Chu (2018). "Preparation and characterization of DOPOITA modified ethyl cellulose and its application in phenolic foams." Polymers 10(10): 1049.

Mabel, M., T. Sundararaman, N. Parthasarathy and J. Rajkumar (2019). "Chitin Beads from Peneaus sp. Shells as a Biosorbent for Methylene Blue Dye Removal." Polish Journal of Environmental Studies 28(4). 
Malik, P. K. (2003). "Use of activated carbons prepared from sawdust and rice-husk for adsorption of acid dyes: a case study of Acid Yellow 36." Dyes and pigments 56(3): 239-249.

Marr, H. E., J. M. Stewart and M. Chiu (1973). "The crystal structure of methylene blue pentahydrate." Acta Crystallographica Section B: Structural Crystallography and Crystal Chemistry 29(4): 847-853.

Mckay, G., G. Ramprasad and P. Mowli (1987). "Desorption and regeneration of dye colours from low-cost materials." Water Research 21(3): 375-377.

Melo, B. C., F. A. Paulino, V. A. Cardoso, A. G. Pereira, A. R. Fajardo and F. H. Rodrigues (2018). "Cellulose nanowhiskers improve the methylene blue adsorption capacity of chitosan-g-poly (acrylic acid) hydrogel." Carbohydrate polymers 181: 358-367.

Mohammed, N., H. Lian, M. S. Islam, M. Strong, Z. Shi, R. M. Berry, H.-Y. Yu and K. C. Tam (2021). "Selective adsorption and separation of organic dyes using functionalized cellulose nanocrystals." Chemical Engineering Journal 417: 129237.

Mohan, S. V. and J. Karthikeyan (1997). "Removal of lignin and tannin colour from aqueous solution by adsorption onto activated charcoal." Environmental Pollution 97(1-2): 183-187.

$\mathrm{Na}$, C. (2020). "Size-controlled capacity and isocapacity concentration in Freundlich adsorption." ACS omega 5(22): 13130-13135.

Naderi, A., T. Lindström, J. Sundström, T. Pettersson, G. Flodberg and J. Erlandsson (2015). "Microfluidized carboxymethyl cellulose modified pulp: a nanofibrillated cellulose system with some attractive properties." Cellulose 22(2): 1159-1173.

Naidja, L. (2010). "Elimination du colorant orange II en solution aqueuse, par voie photochimique et par adsorption."

Narayanan, R. K., N. K. Nethran, S. J. Devaki and T. P. Rao (2014). "Robust polymeric hydrogel using rod-like amidodiol as crosslinker: Studies on adsorption kinetics and mechanism using dyes as adsorbate." Journal of Applied Polymer Science 131(18).

Ning, F., J. Zhang, M. Kang, C. Ma, H. Li and Z. Qiu (2020). "Hydroxyethyl cellulose hydrogel modified with tannic acid as methylene blue adsorbent." Journal of Applied Polymer Science 138(8): 49880.

Ning, F., J. Zhang, M. Kang, C. Ma, H. Li and Z. Qiu (2021). "Hydroxyethyl cellulose hydrogel modified with tannic acid as methylene blue adsorbent." Journal of Applied Polymer Science 138(8): 49880.

Pagga, U. and D. Brown (1986). "The degradation of dyestuffs: Part II Behaviour of dyestuffs in aerobic biodegradation tests." Chemosphere 15(4): 479-491.

Pan, Y., J. Wang, C. Sun, X. Liu and H. Zhang (2016). "Fabrication of highly hydrophobic organic-inorganic hybrid magnetic polysulfone microcapsules: A lab-scale feasibility study for removal of oil and organic dyes from environmental aqueous samples." Journal of hazardous materials 309: 65-76.

Park, J.-H., Y. S. Ok, S.-H. Kim, J.-S. Cho, J.-S. Heo, R. D. Delaune and D.-C. Seo (2016). "Competitive adsorption of heavy metals onto sesame straw biochar in aqueous solutions." Chemosphere 142: 77-83.

Pelalak, R., R. Soltani, Z. Heidari, R. E. Malekshah, M. Aallaei, A. Marjani, M. Rezakazemi, T. A. Kurniawan and S. Shirazian (2021). "Molecular dynamics simulation of novel diamino-functionalized hollow mesosilica spheres for adsorption of dyes from synthetic wastewater." Journal of Molecular Liquids 322: 114812.

Pradeep, T. (2009). "Noble metal nanoparticles for water purification: a critical review." Thin solid films 517(24): 6441-6478.

Rafatullah, M., O. Sulaiman, R. Hashim and A. Ahmad (2010). "Adsorption of methylene blue on low-cost adsorbents: a review." Journal of hazardous materials 177(1-3): 70-80.

Rager, T., A. Geoffroy, R. Hilfiker and J. M. Storey (2012). "The crystalline state of methylene blue: a zoo of hydrates." Physical Chemistry Chemical Physics 14(22): 8074-8082.

Rao, Z., H. Ge, L. Liu, C. Zhu, L. Min, M. Liu, L. Fan and D. Li (2018). "Carboxymethyl cellulose modified graphene oxide as $\mathrm{pH}$-sensitive drug delivery system." International journal of biological macromolecules 107: 1184-1192.

Saadi, R., Z. Saadi, R. Fazaeli and N. E. Fard (2015). "Monolayer and multilayer adsorption isotherm models for sorption from aqueous media." Korean Journal of Chemical Engineering 32(5): 787-799.

Saraydın, D., Y. Işıkver and E. Karadağ (2018). "A Study on the correlation between adsorption and swelling for poly (Hydroxamic Acid) hydrogels-triarylmethane dyes systems." Journal of Polymers and the Environment 26(9): 3924-3936.

Sbai, G., K. Oukili and M. Loukili (2016). "Etude de la dégradation des colorants de textile application sur le Bleu de Méthylène [Study of the degradation of the colouring agents of textile application on the Methylene blue]." International Journal of Innovation and Applied Studies 16(2): 272.

Senna, A. M., K. M. Novack and V. R. Botaro (2014). "Synthesis and characterization of hydrogels from cellulose acetate by esterification crosslinking with EDTA dianhydride." Carbohydrate polymers 114: 260-268. 
Senna, A. M., K. M. Novak, J. B. do Carmo and V. R. Botaro (2013). "Synthesis and characterization of hydrogels from cellulose acetate by esterification crosslinking with EDTA dianhydride." $\underline{B l u c h e r}$ Chemistry Proceedings 1(2): 300-300.

Senthil Kumar, P., P. S. A. Fernando, R. T. Ahmed, R. Srinath, M. Priyadharshini, A. Vignesh and A. Thanjiappan (2014). "Effect of temperature on the adsorption of methylene blue dye onto sulfuric acidtreated orange peel." Chemical Engineering Communications 201(11): 1526-1547.

Silverstein, R., G. Bassler and T. Morrill (1991). Spectrometric identification of organic molecules, John Wiley and Sons, NY, USA. Google Scholar.

Sips, R. (1948). "On the structure of a catalyst surface." The journal of chemical physics 16(5): 490-495.

Skopp, J. (2009). "Derivation of the Freundlich adsorption isotherm from kinetics." Journal of Chemical Education 86(11): 1341.

Somera, L. R., R. Cuazon, J. K. Cruz and L. J. Diaz (2019). Kinetics and isotherms studies of the adsorption of $\mathrm{Hg}$ (II) onto iron modified montmorillonite/polycaprolactone nanofiber membrane. IOP Conference Series: Materials Science and Engineering, IOP Publishing.

Stîngă, G., A. Băran, A. Iovescu, F. Brânzoi and D.-F. Anghel (2021). "Impact of cationic surfactant on fluorescent complex of pyrene labeled poly (acrylic acid) and methylene blue." Journal of Molecular Liquids 322: 114545.

Sukumaran, V. S. and A. Ramalingam (2011). "Third Order Optical Nonlinearities and Spectral Characteristics of Methylene Blue." J. Quantum Information Science 1(2): 69-72.

TABAGHT, F. E., A. EL IDRISSI, M. AQIL, A. BENAHEMAD, S. EL BARKANY, R. BELLAOUCHI and A. ASEHRAOU "SYNTHESIS AND CHARACTERIZATION OF (THIO) CARBAMATES BASED ON CELLULOSE AND CELLULOSE ACETATE: BIODEGRADATION AND SOLUBILITY STUDIES."

Tenorio-Alfonso, A., M. C. Sánchez and J. M. Franco (2019). "Synthesis and mechanical properties of biosourced polyurethane adhesives obtained from castor oil and MDI-modified cellulose acetate: Influence of cellulose acetate modification." International Journal of Adhesion and Adhesives 95: 102404.

Thabet, M. S. and A. M. Ismaiel (2016). "Sol-Gel $\gamma$-Al 2 O 3 Nanoparticles Assessment of the Removal of Eosin Yellow Using: Adsorption, Kinetic and Thermodynamic Parameters." Journal of Encapsulation and Adsorption Sciences 6(03): 70.

Tsuda, S., N. Matsusaka, H. Madarame, S. Ueno, N. Susa, K. Ishida, N. Kawamura, K. Sekihashi and Y. F. Sasaki (2000). "The comet assay in eight mouse organs: results with 24 azo compounds." Mutation Research/Genetic Toxicology and Environmental Mutagenesis 465(1-2): 11-26.

Uddin, M. T., M. A. Islam, S. Mahmud and M. Rukanuzzaman (2009). "Adsorptive removal of methylene blue by tea waste." Journal of Hazardous Materials 164(1): 53-60.

Vandevivere, P. C., R. Bianchi and W. Verstraete (1998). "Treatment and reuse of wastewater from the textile wet-processing industry: Review of emerging technologies." Journal of Chemical Technology \& Biotechnology: International Research in Process, Environmental AND Clean Technology 72(4): 289302.

Wang, G., J. Zhang, S. Lin, H. Xiao, Q. Yang, S. Chen, B. Yan and Y. Gu (2020). "Environmentally friendly nanocomposites based on cellulose nanocrystals and polydopamine for rapid removal of organic dyes in aqueous solution." Cellulose 27(4): 2085-2097.

Wang, H., B. Wang, J. Li and T. Zhu (2019). "Adsorption equilibrium and thermodynamics of acetaldehyde/acetone on activated carbon." Separation and Purification Technology 209: 535-541.

Wang, W., Y. Zhao, H. Bai, T. Zhang, V. Ibarra-Galvan and S. Song (2018). "Methylene blue removal from water using the hydrogel beads of poly (vinyl alcohol)-sodium alginate-chitosan-montmorillonite." Carbohydrate polymers 198: 518-528.

Wang, X., J. He, L. Ma, B. Yan, L. Shi and R. Ran (2020). "Self-assembling graphene oxide/modified amphipathic hydroxyethyl cellulose hybrid stabilized Pickering emulsion polymerization for functional hydrogel." Colloids and Surfaces A: Physicochemical and Engineering Aspects: 125742.

Wang, Y.-Y., Y.-X. Liu, H.-H. Lu, R.-Q. Yang and S.-M. Yang (2018). "Competitive adsorption of Pb (II), Cu (II), and $\mathrm{Zn}$ (II) ions onto hydroxyapatite-biochar nanocomposite in aqueous solutions." Journal of Solid State Chemistry 261: 53-61.

Weber Jr, W. J., T. C. Voice, M. Pirbazari, G. E. Hunt and D. M. Ulanoff (1983). "Sorption of hydrophobic compounds by sediments, soils and suspended solids-II. Sorbent evaluation studies." Water Research 17(10): 1443-1452.

Weng, C.-H. and Y.-F. Pan (2007). "Adsorption of a cationic dye (methylene blue) onto spent activated clay." Journal of Hazardous Materials 144(1-2): 355-362.

Wilson, T. M. (1907). "On the chemistry and staining properties of certain derivatives of the methylene blue group when combined with eosin." The Journal of experimental medicine 9(6): 645.

Worch, E. (2012). "Adsorption Equilibrium: General Aspects and Single-Solute Adsorption." Adsorption Technology in Water Treatment-Fundamentals, Processes, and Modeling: 42-76. 
Wu, C.-H., C.-Y. Kuo, C.-F. Lin and S.-L. Lo (2002). "Modeling competitive adsorption of molybdate, sulfate, selenate, and selenite using a Freundlich-type multi-component isotherm." Chemosphere 47(3): 283-292.

Wu, C.-H., S.-L. Lo and C.-F. Lin (2000). "Competitive adsorption of molybdate, chromate, sulfate, selenate, and selenite on $\gamma$-A12O3." Colloids and Surfaces A: Physicochemical and Engineering Aspects 166(1-3): 251-259.

Xia, G. and W. P. Ball (1999). "Adsorption-partitioning uptake of nine low-polarity organic chemicals on a natural sorbent." Environmental science \& technology 33(2): 262-269.

Yang, X., Z. Li, H. Liu, L. Ma, X. Huang, Z. Cai, X. Xu, S. Shang and Z. Song (2020). "Cellulose-based polymeric emulsifier stabilized poly ( $\mathrm{N}$-vinylcaprolactam) hydrogel with temperature and $\mathrm{pH}$ responsiveness." International Journal of Biological Macromolecules 143: 190-199.

Younes, M. M., I. I. El-sharkawy, A. Kabeel, K. Uddin, A. Pal, S. Mitra, K. Thu and B. B. Saha (2019). "Synthesis and characterization of silica gel composite with polymer binders for adsorption cooling applications." International Journal of Refrigeration 98: 161-170.

Yu, S., X. Wang, Y. Ai, X. Tan, T. Hayat, W. Hu and X. Wang (2016). "Experimental and theoretical studies on competitive adsorption of aromatic compounds on reduced graphene oxides." Journal of Materials Chemistry A 4(15): 5654-5662.

Yurdakoç, M., Y. Seki, S. Karahan and K. Yurdakoç (2005). "Kinetic and thermodynamic studies of boron removal by Siral 5, Siral 40, and Siral 80." Journal of Colloid and Interface Science 286(2): 440-446.

Zafar, S., F. Aqil and I. Ahmad (2007). "Metal tolerance and biosorption potential of filamentous fungi isolated from metal contaminated agricultural soil." Bioresource technology 98(13): 2557-2561.

Zannagui, C., H. Amhamdi, S. El Barkany, I. Jilal, O. Sundman, A. Salhi, S. Chaouf, M. Abou-Salama, A. El Idrissi and M. Zaghrioui (2020). "Design, Characterization and Investigation of Heavy Metal Ions Removal by New Cellulose-Ether Based adsorbent." Moroccan Journal of Chemistry 8(1): 8-1 (2020) 2332-2346.

Zare, E. N., A. Motahari and M. Sillanpää (2018). "Nanoadsorbents based on conducting polymer nanocomposites with main focus on polyaniline and its derivatives for removal of heavy metal ions/dyes: A review." Environmental research 162: 173-195.

Zhang, L., J. Wei, X. Zhao, F. Li, F. Jiang, M. Zhang and X. Cheng (2016). "Competitive adsorption of strontium and cobalt onto tin antimonate." Chemical Engineering Journal 285: 679-689.

Zhi, Z., B. Ma, S. Jian, Y. Guo, H. Yu, H. Tan and F. Chen (2017). "Thermal analyses." Journal of Thermal Analysis and Calorimetry 129(3): 1547-1554. 